\title{
DFT Investigations of the Magnetic Properties of Actinide Complexes
}

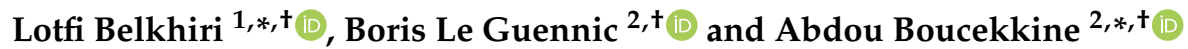 \\ 1 Laboratoire de Physique Mathématique et Subatomique LPMS, Faculté des Sciences Exactes, \\ Université des Frères Mentouri Constantine 1, Constantine 25017, Algeria \\ 2 Univ Rennes, CNRS, ISCR (Institut des Sciences Chimiques de Rennes) - UMR 6226, F-35000 Rennes, France; \\ boris.leguennic@univ-rennes1.fr \\ * Correspondence: lotfi.belkhiri@umc.edu.dz (L.B.); abdou.boucekkine@univ-rennes1.fr (A.B.); \\ Tel.: +3-32-2323-6269 (A.B.) \\ + Equal contribution.
}

Received: 4 January 2019; Accepted: 8 February 2019; Published: 17 February 2019

check for updates

\begin{abstract}
Over the past 25 years, magnetic actinide complexes have been the object of considerable attention, not only at the experimental level, but also at the theoretical one. Such systems are of great interest, owing to the well-known larger spin-orbit coupling for actinide ions, and could exhibit slow relaxation of the magnetization, arising from a large anisotropy barrier, and magnetic hysteresis of purely molecular origin below a given blocking temperature. Furthermore, more diffuse $5 \mathrm{f}$ orbitals than lanthanide $4 \mathrm{f}$ ones (more covalency) could lead to stronger magnetic super-exchange. On the other hand, the extraordinary experimental challenges of actinide complexes chemistry, because of their rarity and toxicity, afford computational chemistry a particularly valuable role. However, for such a purpose, the use of a multiconfigurational post-Hartree-Fock approach is required, but such an approach is computationally demanding for polymetallic systems-notably for actinide ones_-and usually simplified models are considered instead of the actual systems. Thus, Density Functional Theory (DFT) appears as an alternative tool to compute magnetic exchange coupling and to explore the electronic structure and magnetic properties of actinide-containing molecules, especially when the considered systems are very large. In this paper, relevant achievements regarding DFT investigations of the magnetic properties of actinide complexes are surveyed, with particular emphasis on some representative examples that illustrate the subject, including actinides in Single Molecular Magnets (SMMs) and systems featuring metal-metal super-exchange coupling interactions. Examples are drawn from studies that are either entirely computational or are combined experimental/computational investigations in which the latter play a significant role.
\end{abstract}

Keywords: actinides; uranium complexes; magnetochemistry; Super-exchange; SMM; DFT

\section{Introduction}

During recent decades, the magnetochemistry of actinide complexes has gained an important impetus, not only at the experimental level, but also at the theoretical one [1-8]. Indeed, since the first observation early in the 1990s of the antiferromagnetic (AF) coupling between uranium(V) centers in the para-imido $\left[\left(\mathrm{MeC}_{5} \mathrm{H}_{4}\right)_{3} \mathrm{U}_{2}\left(\mu-1,4-\mathrm{N}_{2} \mathrm{C}_{6} \mathrm{H}_{4}\right)\right.$ complex by Rosen et al. [9], this class of binuclear actinide systems has been arousing interest [10-52]. Moreover, the discovery in 2009 of the slow magnetic relaxation for the mononuclear complex $\mathrm{U}\left(\mathrm{Ph}_{2} \mathrm{BPz}_{2}\right)_{3}$ [53], which is a signature of a single-molecule magnet (SMM) behavior, has motivated more research, even though lanthanide SMMs have been described in the literature for a longer time [54,55]. A growing number of uranium-containing systems [56-69]-mononuclear as well as binuclear species-have been 
synthesized to develop SMMs; the results have been the subject of recent reviews [70-75]. Such systems are of great interest, owing to the well-known larger spin-orbit coupling for actinide than for lanthanide ions [72], and the more diffuse $5 f$ orbitals (5f covalency) [63,76-78] than the lanthanide $4 \mathrm{f}$ ones, which could lead to strong magnetic super-exchange [53]. Therefore, these unique features of actinides relatively to transition metals and lanthanides open the way to the design of new actinide-based SMMs with high blocking temperatures [71,72,75]. Moreover, over the last twenty years, much effort has been devoted to investigating the magnetic properties of actinide complexes by quantum chemical methods [62-65,67,70-76,79-81]. Indeed, investigating the electronic structure of actinide complexes is essential to understanding their magnetic behavior [1,2,71-73]. However, for such a purpose, the use of a multiconfigurational post-Hartree-Fock approach is required, as stated by several authors $[63,64,82,83]$, but such an approach is computationally demanding (vide infra) for polymetallic systems, notably for actinide ones, and usually simplified models are computed instead of the actual systems [63,64]. Thus, Density Functional Theory (DFT) appears as an alternative tool to compute magnetic exchange coupling and to explore the electronic structure and magnetic properties of actinide-containing molecules, especially when the considered systems are very large $[6,8,21,37,60,79,80,84,85]$. Indeed, DFT emerged in the early 2000 s as a powerful technique, particularly when used in combination with the hybrid B3LYP functional $[86,87]$ and the Broken-Symmetry (BS) Noodleman's approach [88,89], for satisfactory simulations of magnetic properties. This is true not only in the case of d-transition metal systems [82,83,90-104], but also for actinide-containing molecules [105-107]. It is worth noting that actinide-based SMMs are multiconfigurational systems, and the use of the monodeterminantal approach with DFT is a subject of debate [63,108-110].

We present here a review of relevant achievements regarding DFT investigations of the magnetic properties of actinide complexes. This review will also deal with representative examples that illustrate the subject, including actinides in SMMs and systems featuring metal-metal exchange coupling interactions. We focus on studies that are either entirely computational or are combined experimental/computational investigations in which the latter play a significant role.

\section{Survey of Molecules Potentially Exhibiting Magnetic Behavior}

\subsection{Magnetic Coupling Interactions}

Actinide complexes exhibiting magnetic exchange properties are rarely mentioned in the literature [1,2], relatively to the rich d-transition metal magnetochemistry. Most documented cases involve diuranium(V) systems [8,23-27,37,49-51,106,111-116], and only a few studies of magnetic coupling in diuranium(III) and (IV) complexes or mixed uranium(IV)-transition metal have been reported [46,52,105,107,117-122]. Among them, remarkable examples of unusual $\mathrm{U}(\mathrm{V})-\mathrm{U}(\mathrm{V})$ coupling involving a pentavalent bis(imido) uranium dimer [106] and within diuranium(V) dioxo diamond cores $[46,49,114-116,123-126]$ have been reported, which can exhibit Néel temperatures of up to 70 and even $110 \mathrm{~K}[23,24,27,114,115,127]$.

Magnetic coupling constants J were estimated in the 1990s for $\mathrm{U}^{\mathrm{V}} / \mathrm{U}^{\mathrm{V}}$ dinuclear complexes such as the $\mathrm{AF}\left[\left(\mathrm{MeC}_{5} \mathrm{H}_{4}\right)_{3} \mathrm{U}_{2}\left(\mu-1,4-\mathrm{N}_{2} \mathrm{C}_{6} \mathrm{H}_{4}\right)\right.$ species $\left(\mathrm{J}=-19 \mathrm{~cm}^{-1}\right)[1,2,9]$, and later for ferromagnetic $\mathrm{U}^{\mathrm{IV}} / \mathrm{U}^{\mathrm{IV}}$ coupling in $\mathrm{U}_{2}$ Co pyrazolate (cyclam) $\mathrm{Co}\left[(\mu-\mathrm{Cl}) \mathrm{U}\left(\mathrm{Me}_{2} \mathrm{Pz}\right)_{4}\right]_{2}$ system $\left(15 \mathrm{~cm}^{-1} \geq \mathrm{J} \geq 48\right.$ $\left.\mathrm{cm}^{-1}\right)$ [21] and in the arene-bridged uranium(IV) complex $\mathrm{U}\left[\mathrm{HC}\left(\mathrm{SiMe}_{2} \mathrm{Ar}\right)_{2}\left(\mathrm{SiMe}_{2}-\mu-\mathrm{N}\right)\right](\mu-\mathrm{Ar}) \mathrm{U}\left(\mathrm{Ts}^{\mathrm{Xy}}\right)$ $\left(\mathrm{J}=20 \mathrm{~cm}^{-1}\right)$ [38]. As expected for the more ionic uranium(IV) species, reports of $\mathrm{U}^{\mathrm{IV}} / \mathrm{U}^{\mathrm{IV}}$ couplings are rather scarce, being limited to few examples $[33,105,107,122,128]$ discussing couplings which are mediated by either chalcogen bridges or aromatic spacers. Moreover, examples of uranium(IV)-copper(II) and uranium(IV)-nickel(II) couplings have been reported [43-45,117,118]. It is noteworthy that a successful strategy to promote interactions between paramagnetic actinide ions has been the use of covalently-linked bridging ligands [1,2]. Thus, a great variety of spacer ligands bearing two functionalized actinide centers have been tested, showing significant metal-metal communication 
and magnetic interaction. For example, the linear bis(imido) (imido $=1,4$-diimidobenzene) covalent linkage was the first one used in the diuranium(V) para- and meta-bridged complexes (Figure 1) [9].

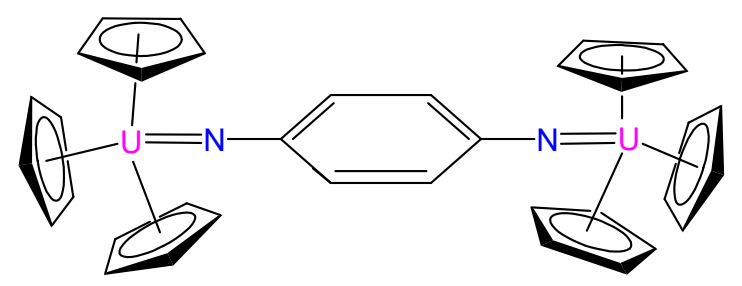

Figure 1. The diuranium(V) imido complex which exhibits AF U...U coupling [9].

More recently, reports of Kiplinger's group [106,112,128] on ketimide actinide-containing assemblies, indicated that the 1,4-phenylenediketimide ligand could lead to diverse and interesting magnetic behavior. In their study, bis(ketimide) $\left[\left(\mathrm{C}_{5} \mathrm{Me}_{4} \mathrm{Et}\right)_{2}(\mathrm{Cl}) \mathrm{An}\right]_{2}\left(\mu-\left\{\mathrm{N}=\mathrm{CMe}-\left(\mathrm{C}_{6} \mathrm{H}_{4}\right)-\mathrm{MeC}=\mathrm{N}\right\}\right)$ binuclear $\mathrm{An}^{\mathrm{IV}} / \mathrm{An}^{\mathrm{IV}}$ (Th, U) complexes ${ }^{62}$ were synthesized (Figure 2). The authors reported that, although evidence for magnetic coupling between metal centers in the bimetallic $\mathrm{U}^{\mathrm{IV}} / \mathrm{U}^{\mathrm{IV}}\left(5 \mathrm{f}^{2}-5 \mathrm{f}^{2}\right)$ complex is ambiguous, the complex displays appreciable electronic communication between the metal centers through the $\pi$ system of the dianionic bis(ketimide) dianionic bridging ligand [128].

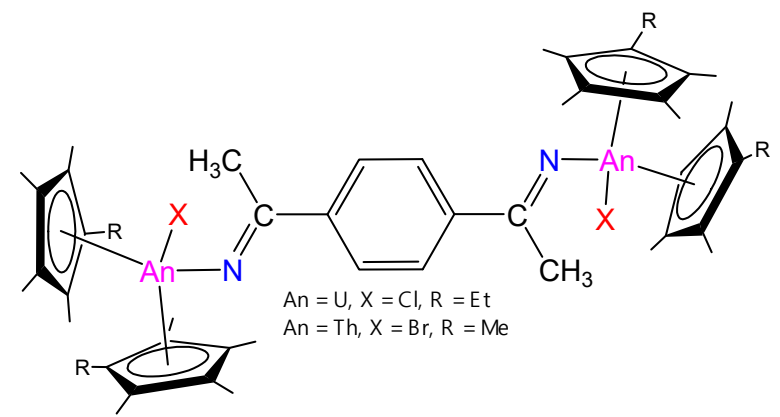

Figure 2. Structure of the bis(ketimide)-bridged $\left[\left(\mathrm{C}_{5} \mathrm{Me}_{4} \mathrm{Et}\right)_{2}(\mathrm{Cl}) \mathrm{An}\right]_{2}\left(\mu-\left\{\mathrm{N}=\mathrm{CMe}-\left(\mathrm{C}_{6} \mathrm{H}_{4}\right)-\mathrm{MeC}=\mathrm{N}\right\}\right)$ binuclear $\mathrm{An}^{\mathrm{IV}} / \mathrm{An}^{\mathrm{IV}}$ (Th, U) complexes (ketimide = 1,4-phenylenediketimide) [128].

Another kind of bridging-spacer system includes inverted-sandwich systems, which contain two uranium atoms bridged by a cyclic aromatic hydrocarbon ligand e.g., benzene, toluene (Figure 3) [9], cycloheptatrienyl $\left(\eta^{7}-\mathrm{C}_{7} \mathrm{H}_{7}\right)$ or naphthalene and cyclooctatetraene $\left(\eta^{8}-\mathrm{C}_{8} \mathrm{H}_{8}\right)$, as recently reviewed [127]. Indeed, Cummins and Coll. [10] reported in the 2000s the X-ray structure of the first inverted-sandwich structures of different arene spacers, namely the $\left(\mu-\eta^{6}: \eta^{6}-\mathrm{C}_{7} \mathrm{H}_{8}\right)\left[\mathrm{U}(\mathrm{N}[\mathrm{R}] \mathrm{Ar})_{2}\right]_{2}$ complex $\left(\mathrm{R}=\mathrm{C}\left(\mathrm{CH}_{3}\right)_{3}, \mathrm{Ar}=3,5-\mathrm{C}_{6} \mathrm{H}_{3} \mathrm{Me}_{2}\right)$ (Figure 3), in which a toluene molecule bridges two uranium bis-amido fragments in a symmetrical $\eta^{6}: \eta^{6}$ mode, involving covalent delta bonds. These aromatic ligands, which could exhibit rich redox chemistry for a range of reducible substrates, have been proposed to promote intra-molecular electronic and magnetic communications between uranium centers [65]. This class of inverted-sandwich structures was enriched in 2011 by the first arene-bridged diuranium(III) [\{U-(BIPM $\left.\left.\left.{ }^{\mathrm{TMS}} \mathrm{H}\right)(\mathrm{I})\right\}_{2}\left(\mu-\eta^{6}: \eta^{6}-\mathrm{C}_{6} \mathrm{H}_{5} \mathrm{Me}\right)\right]$ system exhibiting SMM behavior [60].

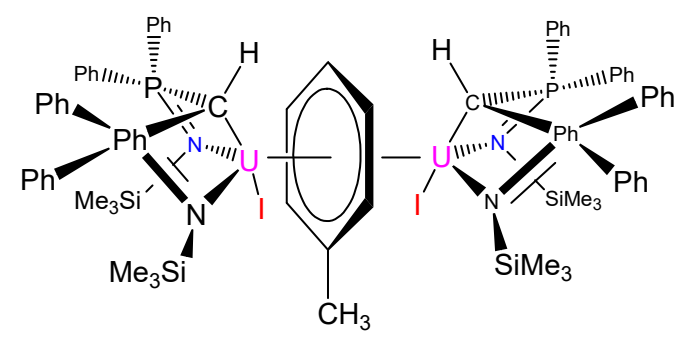

Figure 3. Structure of the arene-bridged uranium(III) $\left.\left.\left(\mathrm{BIPM}^{\mathrm{TMS}} \mathrm{H}\right)(\mathrm{I})\right\}_{2}\left(\mu-\eta^{6}: \eta^{6}-\mathrm{C}_{6} \mathrm{H}_{5} \mathrm{Me}\right)\right]$ SMM [60]. 
The formulation of the metal oxidation state in this species could either be uranium(II)/neutral arene, uranium(III)/dianionic arene, or uranium(IV)/tetraanionic arene, but spectroscopic characterization and theoretical computations favor uranium(III)/dianionic arene formulation [127]. Cummins and Coll. [11] have extended this inverted-sandwich series of complexes to the naphthalene-bridged $\mathrm{M}_{2}\left(\mu-\eta^{6}, \eta^{6}-\mathrm{C}_{10} \mathrm{H}_{8}\right)\left[\mathrm{U}\left(\mathrm{NC}\left[{ }^{\mathrm{t}} \mathrm{Bu}\right] \mathrm{Mes}\right)_{3}\right]_{2}\left(\mathrm{M}=\mathrm{K}, \mathrm{Na}\right.$; Mes = 2,4,6- $\left.\mathrm{C}_{6} \mathrm{H}_{2} \mathrm{Me}_{3}\right)$ and its cyclooctatetraene $\left(\mu-\eta^{8}, \eta^{8}-\mathrm{C}_{8} \mathrm{H}_{8}\right) \mathrm{U}_{2}\left(\mathrm{NC}\left[{ }^{\mathrm{t}} \mathrm{Bu}\right] \mathrm{Mes}\right)_{6}$ congener. As reported by these authors, the performed DFT computations on the $\left[\left(\mu-\eta^{8}, \eta^{8}-\mathrm{C}_{10} \mathrm{H}_{8}\right) \mathrm{U}_{2}\left(\mathrm{NCH}_{2}\right)_{6}\right]^{2-}$ and $\left(\mu-\eta^{8}, \eta^{8}-\mathrm{C}_{8} \mathrm{H}_{8}\right) \mathrm{U}_{2}\left(\mathrm{NCH}_{2}\right)_{6}$ models in their quintet state $(\mathrm{S}=2)$ are consistent with the tetravalent $\mathrm{U}^{\mathrm{IV}}\left(5 \mathrm{f}^{2}\right)$ oxidation state of the metal centers [11]. The $\mathrm{C}-\mathrm{C}$ bond lengths of the bridging arene were found to be slightly lengthened compared to those of free toluene, and with the help of theoretical calculations, suggested $\delta$-back-bonding between uranium and the arene ring. In 2004, William J. Evans and Coll. [19] reported the structure, reactivity and DFT analysis of the two arene-bridged diuranium $\left[\left(\mathrm{Mes}\left({ }^{\mathrm{t}} \mathrm{Bu}\right) \mathrm{N}\right)_{2} \mathrm{U}_{2}\left(\mu-\eta^{6}: \eta^{6}-\mathrm{C}_{7} \mathrm{H}_{8}\right)\right.$ and $\left[\left(\eta^{5}-\mathrm{C}_{5} \mathrm{Me}_{5}\right)_{2} \mathrm{U}\right]_{2}\left(\mu-\eta^{6}: \eta^{6}-\mathrm{C}_{6} \mathrm{H}_{6}\right)$ systems. The latter species was described as two $\mathrm{U}(\mathrm{III})$ covalently bonded metals to the arene ligand via $\delta^{\prime}$ symmetry bonding molecular orbital (MO). Ephritikhine and Coll. [119,120] had previously reported a unique bridged-cycloheptatrienyl diuranium $\left[\mathrm{U}\left(\mathrm{BH}_{4}\right)_{2}\left(\mathrm{OC}_{4} \mathrm{H}_{8}\right)_{5}\right]\left[\left(\mu-\eta^{7}, \eta^{7}-\mathrm{C}_{7} \mathrm{H}_{7}\right)\left[\mathrm{U}\left(\mathrm{BH}_{4}\right)_{3}\right]_{2}\right]^{-}$anionic complex. It was suggested that the $\left(\mathrm{C}_{7} \mathrm{H}_{7}\right)^{3-}$ ring should be described as an aromatic planar group and the metals as $\mathrm{U}^{\mathrm{IV}}$ ions, with four highest $\delta$ 'symmetry bonding MOs. Such covalently bridged systems by $\delta$-bonding should promote $\mathrm{U} \cdot \ldots \mathrm{U}$ electronic and magnetic communications $[1,2,35-38,60,65,72,73]$. Although to our knowledge no systematic theoretical studies have been reported on the magnetic behavior of the latter complexes, it seems likely that $\delta$-bonding, which dominates the bonding in the inverse sandwich unit, could favor metal-metal exchange coupling as stated by recent reports evidencing arene-bridged diuranium SMM behavior $[60,72,73]$. Indeed, in their continual efforts to develop new synthetic routes to magnetic actinide systems, S.T. Liddle's group recently (2017) extended their investigations to crystal field and magnetic interactions in diuranium $\left[\left\{\mathrm{U}\left(\operatorname{Tren}^{\mathrm{TIPS}}\right)\right\}_{2}(\mu-\mathrm{E})\right](\mathrm{E}=\mathrm{S}$, $\mathrm{Se}, \mathrm{Te}$ ) bridged-chalcogenide complexes with $\mathrm{U}^{\mathrm{IV}}-\mathrm{E}-\mathrm{U}^{\mathrm{IV}}$ cores (Figure 4) [37], which exhibit linearly U-E-U linked cores.

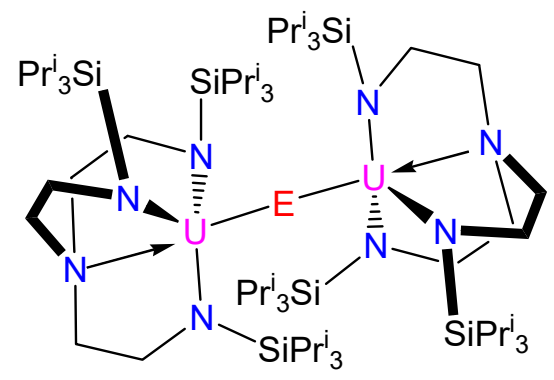

Figure 4. Structure of the diuranium $\mathrm{U}^{\mathrm{IV}} / \mathrm{U}^{\mathrm{IV}}\left[\left\{\mathrm{U}\left(\operatorname{Tren}^{\mathrm{TIPS}}\right)\right\}_{2}(\mu-\mathrm{E})\right](\mathrm{E}=\mathrm{S}, \mathrm{Se}, \mathrm{Te})$ bridged-chalcogenide systems [37].

Plots of the magnetic susceptibility vs. temperature of these linkages present shoulders that could be interpreted as evidence of uranium-uranium magnetic exchange. However, a detailed study using CASSCF computations of their electronic structures revealed that the magnetic properties of these systems can be simply correlated to single-ion crystal field (CF) effects which vary as the nature of the chalcogen varies.

As reviewed recently [71,72], a successful route to super-exchange effects in actinide-containing multinuclear species is through cation-cation interactions (CCI) [23-33,46-51,59,61,69,114-116,123], mostly between uranyl(V) $\mathrm{UO}_{2}{ }^{+}$of actinyl units. This linkage forms an oxo-bridge between metal centers affording a great number of oxo-bridged systems exhibiting significant coupling between $\mathrm{U}^{\mathrm{V}}$ centers $[27,49]$, mixed $U^{\mathrm{V}} /$ transition metal $[28-32,111]$ or lanthanide centers $[47,112,123]$, with the largest actinide-based multinuclear complex affording the unique structure of a wheel-shaped cluster $\left\{\left[\mathrm{UO}_{2} \text { (salen) }\right]_{2} \mathrm{Mn}(\mathrm{Py})_{3}\right\}_{6}\left(\mathrm{Py}=\right.$ pyridine) which is assembled through $\mathrm{UO}_{2}{ }^{+}$and $\mathrm{Mn}^{\mathrm{II}}$ interactions [29]. 
Additionally, CCIs were observed between $\mathrm{Np}^{\mathrm{IV}} / \mathrm{Np}^{\mathrm{V}}$ ions in neptunyl complexes [75]. Beside the great number of synthesized CCI systems, few theoretical studies of their magnetic properties have been carried out $[1-4,7,8,37,60,63,64,71,72,80,81]$.

\section{2. $S M M$ Behavior}

The first actinide system found to display slow magnetic relaxation was the mononuclear uranium(III) [U $\left.\left\{\mathrm{Ph}_{2} \mathrm{~B}\left(\mathrm{~N}_{2} \mathrm{C}_{3} \mathrm{H}_{3}\right)_{2}\right\}_{3}\right]$ complex exhibiting clear SMM behavior (Figure 5) [53]. Since then, a wide range of SMMs based on uranium(III, V) have been reported [56-59,62,127,129-131], which are mainly supported by pyrazolylborate ligands as reviewed recently [69-72,127].

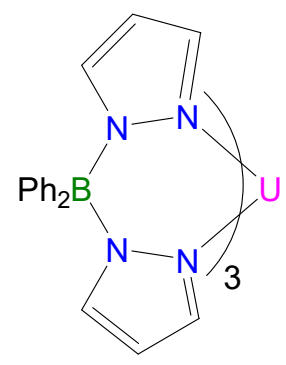

Figure 5. Structure of the uranium(III) $\left[\mathrm{U}\left\langle\mathrm{Ph}_{2} \mathrm{~B}\left(\mathrm{~N}_{2} \mathrm{C}_{3} \mathrm{H}_{3}\right)_{2}\right\}_{3}\right]$ SMM [127].

In 2012, the uranium SMM chemistry was extended to the pentavalent species of $U(V)$ ions, with the report of the nanostructure wheel-shaped $\left.\left[\left(\mathrm{UO}_{2}\left[\left(\mathrm{CH}_{2} \mathrm{NCHC}_{6} \mathrm{H}_{4}-2-\mathrm{O}\right)_{2}\right]\right)_{2}\left(\mathrm{Mn}[\mathrm{Py}]_{3}\right)\right\}_{6}\right]$ complex [61]. As reported, significant magnetic interactions between the uranyl(V) and manganese(II) ions were studied by susceptibility measurements. In 2013, the synthesis of a terminal uranium(V) mono-oxo complex $\mathrm{U}\left(\operatorname{Tren}^{\mathrm{TIPS}}\right)(=\mathrm{O})$ (Figure 6) supported by the sterically demanding ligand $\mathrm{N}\left(\mathrm{CH}_{2} \mathrm{CH}_{2} \mathrm{NSiPr}_{3}{ }_{3}\right)_{3}$ (Tren ${ }^{\mathrm{TIPS}}$ ) ligand was reported by S.T. Liddle and Coll., [127] revealing the first example of an uranium(V) monometallic SMM.

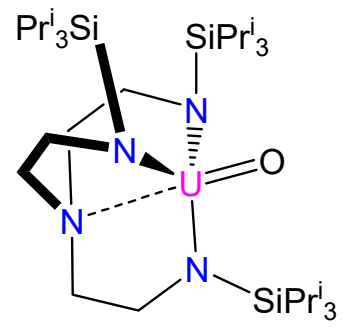

Figure 6. The mononuclear uranium(V) $\mathrm{U}\left(\operatorname{Tren}^{\mathrm{TIPS}}\right)(=\mathrm{O})$ SMM [127].

\section{DFT Investigations of Actinide Complexes Magnetism}

\subsection{Theoretical Approaches for Computing Exchange Coupling Constants}

Magnetic properties of species bearing unpaired electrons are driven by the manifold of states of different spin multiplicities they exhibit, especially if the latter energies are close $[82,83]$. The calculation of magnetic properties of molecular systems, which necessitates a high accuracy of the computed energies, needs to properly take into account both static and dynamic electron correlation. Static correlation is generally well described by multiconfigurational (MC) treatments like CASSCF, whereas dynamical correlation can be recovered with MR-CI techniques or by perturbation using CASPT2 technique, for instance [132-139]. However, CASSCF computations are drastically limited by the size of the active space, so that such high-level computations can only be applied to relatively small molecules or models [82]. DFT could offer the opportunity to estimate the magnetic properties of large systems at a low computational cost $[80-83,90]$. The exact wavefunctions which are eigenfunctions of the square spin operator $\hat{S}^{2}$ with eigenvalues $S(S+1)$ can be written as expansion of Slater determinants each 
of them being eigenfunction of the spin component $\hat{S} z$ [83]. Such exact descriptions of the electronic states of a molecule cannot be obtained using DFT, which is a ground state and single determinant theory; therefore, the exact determination of the electronic states energies cannot be obtained.

Regarding magnetic exchange, the used spin Hamiltonian is the Heisenberg-Dirac-van Vleck (HDvV) one, $\hat{H}=-\Sigma J_{i j} \hat{S}_{i} \cdot \hat{S}_{j}$ where $\hat{S}_{i}, \hat{S}_{j}$ are the spin operators associated to the magnetic centers $i, j$ and $\mathrm{J}_{\mathrm{ij}}$ the coupling constants between these centers [82,83,90,91].

Experimentally, the coupling constants $\mathrm{J}_{\mathrm{ij}}$ are derived from the magnetic susceptibility measurements by fitting the experimental curve. This approach was successfully used by Rinehart and Coll. ${ }^{1}$ to model the susceptibility of the diuranium(V) bis(imido)-bridged complex. As shown in Figure 7 , the best fit of the susceptibility's curve provides an exchange constant of $\mathrm{J}=-19 \mathrm{~cm}^{-1}[1,2]$.

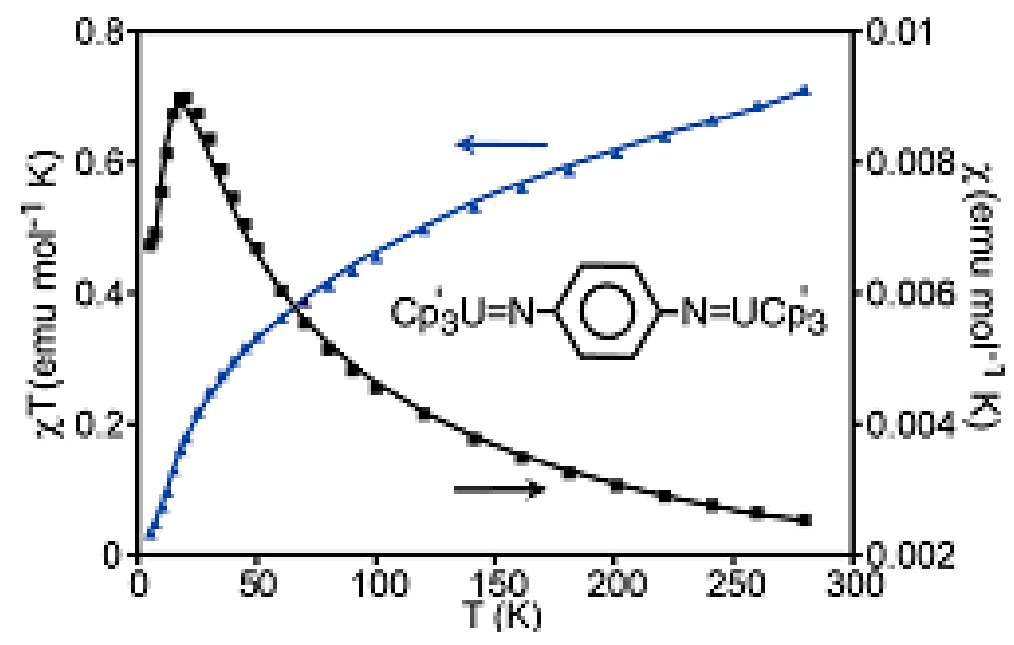

Figure 7. Temperature-dependent magnetic susceptibility $\chi$ (black symbols) of $\left[(\mathrm{MeCp})_{3} \mathrm{U}_{2}\right.$ $\left(\mu-1,4-\mathrm{C}_{6} \mathrm{H}_{4} \mathrm{~N}_{2}\right.$ ) and fits (lines) and the magnetic molar $\chi \mathrm{T}$ versus $\mathrm{T}$ (blue) of the magnetically isolated analog $\left[(\mathrm{MeCp})_{3} \mathrm{U}_{2}\left(\mu-1,3-\mathrm{C}_{6} \mathrm{H}_{4} \mathrm{~N}_{2}\right)\right.$. Susceptibility data (reprinted with permission from [2], American Chemical Society, 2010).

Estimating the coupling constant using DFT is made possible using the Broken Symmetry (BS) approach proposed first by Noodleman et al. [88,89], which have been nicely reviewed by Bencini [82] and Neese [83]. In the case of a dinuclear system, it consists of evaluating the magnetic coupling constant $\mathrm{J}_{\mathrm{ij}}$ from the energy difference between two main configurations, i.e., the high-spin state (HS) of spin $S_{\max }=1$ (in the case of a $5 \mathrm{f}^{1} / 5 \mathrm{f}^{1}$ configuration) which is generally well described by a single determinant and the BS state determinant which is eigenfunction of $\hat{S}_{z}$ with eigenvalue $M_{S}=0$, but not of $\hat{S}^{2}$. In the latter binuclear case, the HS determinant bears the two highest singly occupied molecular orbitals (SOMOs) with spins $\alpha / \alpha$, whereas the BS starting determinant, before running the SCF process, is simply produced from the HS determinant by a spinflip of the electron leading to the $\alpha / \beta$ configuration. Different formulas for the calculation of the coupling constant from the $E_{H S}$ and $\mathrm{E}_{\mathrm{BS}}$ energies have been proposed; ${ }^{42}$ among them, the Yamaguchi et al. formula [140-142]:

$$
J_{12}=\left(\mathrm{E}_{\mathrm{BS}}-\mathrm{E}_{\mathrm{HS}}\right) /\left(<\mathrm{S}^{2}>_{\mathrm{HS}}-<\mathrm{S}^{2}>_{\mathrm{BS}}\right)
$$

where $\left\langle\mathrm{S}^{2}\right\rangle_{\mathrm{HS}}$ and $\left\langle\mathrm{S}^{2}\right\rangle_{\mathrm{BS}}$ are respectively the mean values of the squared spin operator for the HS and BS states.

The validity of the BS approach has been discussed [143], and the reliability and accuracy of the obtained results have been largely investigated [82,83,93-98,133-139]. It has been shown that computations of the magnetic coupling constants at the B3LYP level $[86,87]$ generally lead to satisfying results and good agreement either with high level post-HF computations or with experimental measurements [89]. For instance, D. Gatteschi and Coll. [144] reported DFT calculations 
in 2009 considering a mixed $\{3 \mathrm{~d}-4 \mathrm{f}\}[\mathrm{Cu}(\mathrm{II}) \mathrm{Gd}(\mathrm{III})]$ complex $\left[\mathrm{L}^{1} \mathrm{CuGd}\left(\mathrm{O}_{2} \mathrm{CCF}_{3}\right)_{3}\left(\mathrm{C}_{2} \mathrm{H}_{5} \mathrm{OH}\right)_{2}\right]$ ( $\mathrm{L}^{1}=\mathrm{N}, \mathrm{N}^{\prime}$-bis(3-ethoxy-salicylidene)-1,2-diamino-2-methylpropanato), with the aim of assessing a suitable DFT functional to understand the mechanism of magnetic coupling and to develop magneto-structural correlations. Several GGA, meta-GGA and hybrid functional calculations with different percentages of HF exchange have been performed. The coupling J constant using the $\hat{\mathrm{H}}=$ $\mathrm{J} \hat{\mathrm{S}}_{\mathrm{Gd}} \cdot \hat{\mathrm{S}}_{\mathrm{Cu}}$ spin Hamiltonian, was extracted from the difference energy between the HS state $\left(\mathrm{S}_{\mathrm{T}}=4\right)$ and the BS one, using the following equation:

$$
J=\frac{E_{B S}-E_{H S}}{2 S_{G d} S_{C u}}
$$

The DFT/BS model provides ferromagnetic J constant value of $-5.8 \mathrm{~cm}^{-1}$ (in the used model, negative $J$ value indicates a ferromagnetic character), which is in excellent agreement with the experimental value of $-4.42 \mathrm{~cm}^{-1}$, the B3LYP functional being recommended [144].

\subsection{Magnetic Exchange Coupling in Actinide Bimetallic Systems}

The DFT/BS approach for computing and modeling the exchange coupling interactions faces situations in actinide systems which are different from the lanthanide ones because of their potential for more covalent metal-ligand interactions especially for uranium $[8,21,71-73,75]$. Even so, numerous DFT/BS studies aiming at rationalizing the sign and strength of the exchange coupling for various bridged diuranium by drawing magneto-structural correlations have been carried out [105-110,145-147].

The discovery of the first AF coupled $5 \mathrm{f}^{1} / 5 \mathrm{f}^{1}$ bis(imido) diuranium(V) complex $\left[\left(\left\{\mathrm{MeC}_{5} \mathrm{H}_{4}\right\}_{3} \mathrm{U}\right)_{2}\right.$ $\left(\mu-1,4-\mathrm{N}_{2} \mathrm{C}_{6} \mathrm{H}_{4}\right)$ ] [9], rationalized later [1,127], was undoubtedly a milestone in the field of actinide molecules likely to exhibit magnetic exchange coupling [1-3,6]. One of the first magnetic systems which was theoretically investigated by DFT/BS computations, is the bis(imido) pentavalent diuranium(V) $\left[\mathrm{U}\left(\mathrm{N}^{\mathrm{t} B u}\right)_{2}(\mathrm{I})\left({ }^{\mathrm{t}} \mathrm{Bu}_{2} \text { bpy }\right)\right]_{2}$ complex reported by Kiplinger's group in 2009 [106]. This system exhibits significant $A F$ coupling between the two metallic $5 \mathrm{f}^{1} / 5 \mathrm{f}^{1}$ spin centers, as shown by the magnetic molar $\chi$ versus $\mathrm{T}$, through CCI between $\left[\mathrm{U}(\mathrm{NR})_{2}\right]^{+}$moieties similar to that observed in poly-uranyl $\left[\mathrm{UO}_{2}\right]^{+}$ systems [23-32,46-51,59,61,69,114-116]. The authors carried out B3LYP computations, employing the Stuttgart RSC 1997 ECP basis set for uranium. The geometries of the HS and BS states were optimized with no symmetry constraints. DFT calculations show that the axial $\mathrm{U}=\mathrm{N}$ double bond $(2.073 \AA)$ consists of one $\sigma$ and one $\pi$ bonds, whereas the bridging equatorial $U-N$ bond (2.384 $\AA$ ) is a single bond, as depicted in Figure 8.

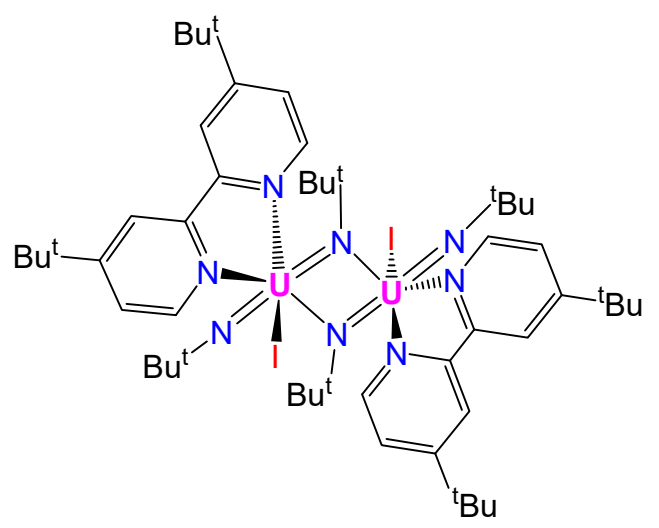

Figure 8. Structure of the $\mathrm{U}_{2} \mathrm{~N}_{2}$ core [106].

Their computations predicted that the BS state is lower in energy than the triplet HS state, leading to an AF exchange coupling constant $\mathrm{J}$ of $-12 \mathrm{~cm}^{-1}$, which is in good agreement with the experimental fitting of the susceptibility measurements. As reported [106], the weak AF coupling between the two $5 \mathrm{f}^{1}$ centers is due not only to the long U-N distance, but also to the fact that half orbitals consist of 
antisymmetric combinations which place a node along the U-N bond. Theoretical insights into the AF interaction between metal centers were assessed using the $\left[\left\{\mathrm{U}(\mathrm{NtBu})_{2}(\mathrm{I})_{2}(\mathrm{bpy})\right\}_{2}\right]$ model to investigate molecular orbital interactions in the $\mathrm{U}_{2} \mathrm{~N}_{2}$ core. As reported by the authors [106], the B3LYP natural orbital analysis shows that the two unpaired SOMO and SOMO- 1 are localized on the uranium centers corresponding to the $5 \mathrm{f}^{1}{ }_{\varphi} / 5 \mathrm{f}^{1}{ }_{\varphi}$ configuration.

One year later, Newell et al. [107] reported in 2010 on the para and meta dinuclear tetravalent $\mathrm{U}^{\mathrm{IV}} / \mathrm{U}^{\mathrm{IV}}\left[\left(\mathrm{NN}^{\prime}{ }_{3}\right)_{2} \mathrm{U}_{2}(\mathrm{DEB})\right]$ and trinuclear $\left[\left(\mathrm{NN}^{\prime}\right)_{3} \mathrm{U}_{3}(\mathrm{TEB})\right]$ complex $\left(\mathrm{NN}^{\prime}{ }_{3}=\left[\mathrm{N}\left(\mathrm{CH}_{2} \mathrm{CH}_{2}\right.\right.\right.$ $\left.\left.\mathrm{NSi}^{\mathrm{t}} \mathrm{BuMe}_{2}\right)_{3}\right]$ ) (Figure 9) containing aromatic arylacetylide ligands i.e., diethynylbenzene (DEB) and triethynylbenzene (TEB) ligands as bridging-spacers for two or three metallic $5 f^{2} / 5 f^{2}$ and $5 f^{2} / 5 f^{2} / 5 f^{2}$ spin centers.

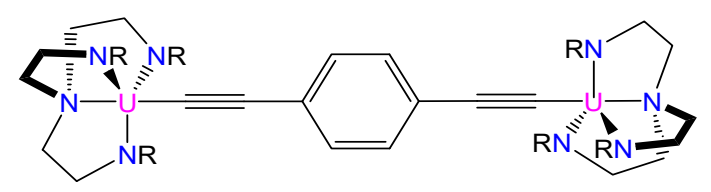

(a)

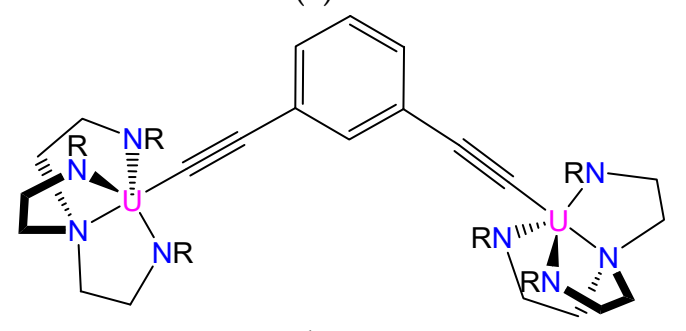

(b)

Figure 9. Molecular structures of the para- (a) and meta-diuranium(IV) (b) [( $\left.\left(\mathrm{NN}^{\prime}\right)_{2} \mathrm{U}_{2}(\mathrm{DEB})\right]$ [107].

As reported by the authors, the experimental investigations of their magnetic properties show that the di- and tri-nuclear compounds appear to display weak magnetic communication between the uranium centers. This communication is modeled by fitting the direct current (DC) magnetic susceptibility data, using the spin Hamiltonian $\hat{H}=-2 J \hat{S}_{z 1} \cdot \hat{S}_{z 2}$, which leads to a weak ferromagnetic coupling constant i.e., $J=4.76,2.75$, and $1.11 \mathrm{~cm}^{-1}$, respectively for meta-, para-diuranium(IV) and triuranium(IV) complexes. As reported in the same study [107], geometry and nuclearity appear to have an effect on the strength of the coupling between the U(IV) centers. Turning back to the theoretical analysis, geometries of the considered model complexes were optimized using B3LYP computations. In these models, the bulky $\mathrm{Si}^{\mathrm{t}} \mathrm{BuMe}_{2}$ substituting groups in the $\mathrm{NN}_{3}^{\prime}$ ligand have been replaced by $\mathrm{H}$ atoms and scalar relativistic effects only included in the used uranium effective core potential. For the simplified models derived from the meta- and para-bridged dinuclear species, the BS approach led to computed J values equal to 1.6 and $-0.1 \mathrm{~cm}^{-1}$ for the meta- and para-bridged complexes, respectively, in fair agreement with experimental trends. As expected, all complexes show only small net spin density (Figure 10) on the ethynylbenzene ligands. As stated by the authors, the computed HS/BS spin densities mapping for meta $(\mathrm{a} / \mathrm{b})$ and para $(\mathrm{c} / \mathrm{d})$ isomers, both show that the spin density is mostly localized on the two $\mathrm{U}^{\mathrm{IV}}$ centers, with no contribution from the bridged-DEB ligand, explaining the weak ferromagnetic and AF character of the meta and para species, respectively [107]. The authors concluded that despite the structural difference with the actual meta and para DEB-bridged dinuclear systems, the result shows that coupling in the single wavenumber range is not unexpected. 


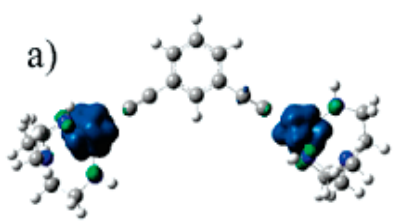

c)

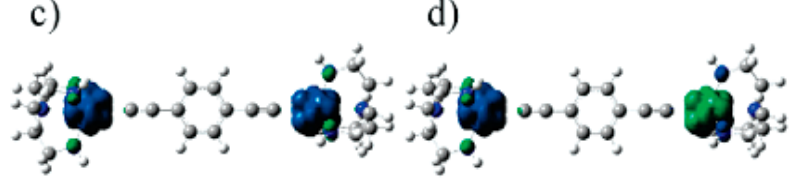

Figure 10. Net spin density plots for HS/BS meta $(\mathbf{a}, \mathbf{b})$ and para $(\mathbf{c}, \mathbf{d})$ DEB-bridged dinuclear species.

(Reprinted with permission from [107], American Chemical Society, 2010).

Subsequent DFT/BS investigations were carried out in 2012 by R. Arratia-Pérez and Coll. [105] on the magnetic properties of the bis(dicyclooctatetraenyl) diuranium(IV) $\left[\mathrm{U}\left(\eta^{8}-\mathrm{C}_{8} \mathrm{H}_{7}\right)_{2}\right]_{2}$ model system (Figure 11). The authors, who used scalar relativistic computations with the Zeroth Order Regular Approximation (ZORA) and the PBE GGA functional [148,149] in combination with the BS approach, found a strong ferromagnetic coupling between the uranium centers bearing the $5 f^{2}-5 f^{2}$ orbitals, the $\mathrm{U} \cdots \mathrm{U}$ distance in the $(\mathrm{COT})_{2} \mathrm{U}^{\mathrm{IV}} \ldots \mathrm{U}^{\mathrm{IV}}(\mathrm{COT})_{2}$ complex being equal to $5.320 \AA$.

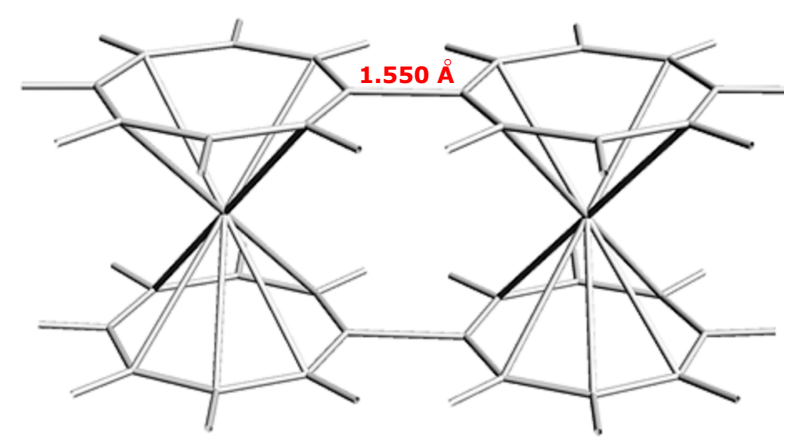

Figure 11. Molecular model for $\left[\mathrm{U}\left(\eta^{8}-\mathrm{C}_{8} \mathrm{H}_{7}\right)_{2}\right]_{2}$ with $\mathrm{D}_{2 \mathrm{~h}}$ symmetry [105].

Returning to the $5 \mathrm{f}^{1}-5 \mathrm{f}^{1}$ bis(imido) diuranium(V) systems [9], the ZORA/B3LYP computations of the coupling constant [146] properly reproduce the AF character of the para $\left[\left(\left\{\mathrm{MeC}_{5} \mathrm{H}_{4}\right\}_{3} \mathrm{U}\right)_{2}\left(\mu-1,4-\mathrm{N}_{2} \mathrm{C}_{6} \mathrm{H}_{4}\right)\right]$ diuranium(V) complex and the ferromagnetic one of its meta isomer $\left[\left(\left\{\mathrm{MeC}_{5} \mathrm{H}_{4}\right\}_{3} \mathrm{U}\right)_{2}\left(\mu-1,3-\mathrm{N}_{2} \mathrm{C}_{6} \mathrm{H}_{4}\right)\right]$ (Figure 12).

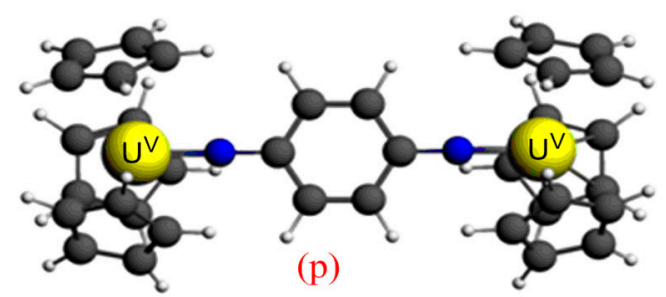

(a)

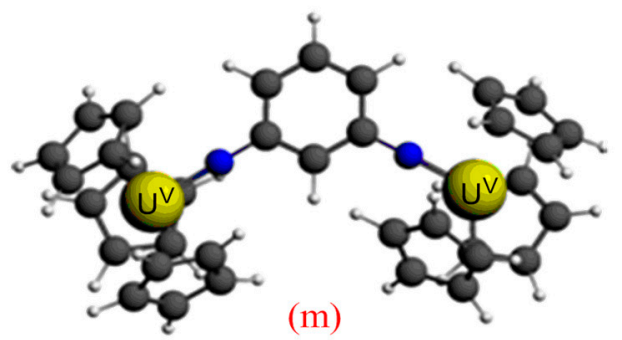

(b)

Figure 12. Structures of the para (a) and meta (b) imido diuranium(V) complexes (reprinted with permission from [146], Elsevier, 2012).

The spin-density plots of the HS/BS states (Figure 13) illustrate that the spin polarization effect is mainly responsible for the observed magnetic character. Considering the para- $\mathrm{U}_{2}$ imido isomer, alternation of the signs of the atomic spin populations along the path is obtained for the BS state and 
not for the HS one. In contrast, for the meta-isomer, alternation of these signs is obtained for the HS state, which is lower in energy than BS one, ensuring the ferromagnetic character of the complex.

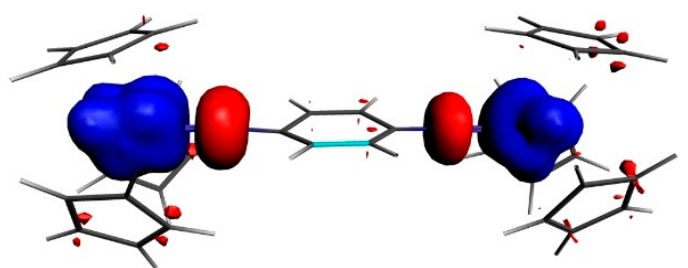

(a)

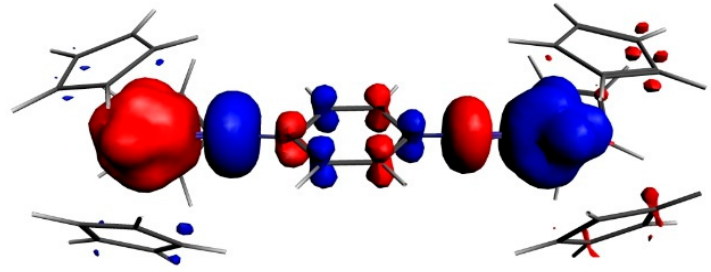

(b)

Figure 13. ZORA/B3LYP spin-density (difference of alpha and beta electron densities) distribution plots for the HS (a) triplet and BS (b) states of para-U2imido (blue color: positive spin density and red color: negative spin density) (reprinted with permission from [146], Elsevier, 2012).

The topology of the path linking the two magnetic of para- $\mathrm{U}_{2}$ imido and meta- $\mathrm{U}_{2}$ imido complexes plays a crucial role for the electronic communication between the $\mathrm{U}(\mathrm{V})$ centers. Furthermore, from the MO point of view, the AF interaction between the two uranium $(\mathrm{V})$ ions mediated by the aromatic imido bridge is mainly due to the effective $\pi$-overlap between $5 f^{1}$ orbitals and the nitrogen orbitals of the bridging ligand groups.

As mentioned, the Kiplinger's group [128] reported in 2008 the occurrence of a significant electronic communication between the $\mathrm{U}^{\mathrm{IV}} / \mathrm{U}^{\mathrm{IV}}\left(5 \mathrm{f}^{2} / 5 \mathrm{f}^{2}\right)$ centers within the bis(ketimide) binuclear $\left[\left(\mathrm{C}_{5} \mathrm{Me}_{4} \mathrm{Et}\right)_{2}(\mathrm{Cl}) \mathrm{An}\right]_{2}\left(\mu-\left\{\mathrm{N}=\mathrm{CMe}-\left(\mathrm{C}_{6} \mathrm{H}_{4}\right)-\mathrm{MeC}=\mathrm{N}\right\}\right) \mathrm{An}^{\mathrm{IV}} / \mathrm{An}^{\mathrm{IV}}(\mathrm{Th}, \mathrm{U})$ complexes. However, the magnetic character of the coupling between the metal centers could not be shown unambiguously. Computationally, the exchange coupling constant has be estimated considering the simplified $\left[\left(\mathrm{C}_{5} \mathrm{H}_{5}\right)_{2}(\mathrm{Cl}) \mathrm{An}\right]_{2}\left(\mu\right.$-ketimide) model $\left(\mathrm{An} / \mathrm{An}=\mathrm{U}^{\mathrm{IV}} / \mathrm{U}^{\mathrm{IV}}\right.$ and $\left.\mathrm{U}^{\mathrm{IV}} / \mathrm{Th}^{\mathrm{IV}}\right)$, where $\mathrm{C}_{5} \mathrm{Me}_{4} \mathrm{Et}$ is replaced by the $\mathrm{Cp}=\mathrm{C}_{5} \mathrm{H}_{5}$ ring (Figure 14) [147]. Using ZORA/B3LYP computations, the BS ground state of these $\mathrm{U}^{\mathrm{IV}} / \mathrm{U}^{\mathrm{IV}} 5 \mathrm{f}^{2}-5 \mathrm{f}^{2}$ complexes has been found of lower energy than the quintet HS state, indicating a weak AF character (estimated coupling constant $|\mathrm{J}|<5 \mathrm{~cm}^{-1}$ ) which has not yet been confirmed experimentally to our knowledge.

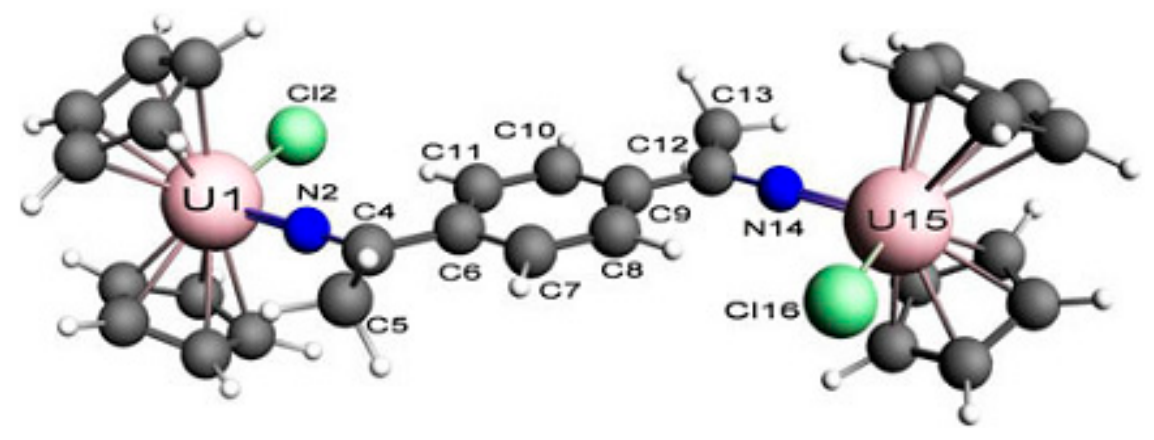

Figure 14. Structures of the bis(ketimide) diuranium(IV) complexes (reprinted with permission from [147], Springer-Verlag, 2012).

The magnetic exchange coupling has been rationalized considering spin density distributions (Figure 15). As obtained for the previous bis(imido) $\mathrm{U}^{\mathrm{V}} / \mathrm{U}^{\mathrm{V}}\left(5 \mathrm{f}^{1} / 5 \mathrm{f}^{1}\right)$ system [146], the AF coupling appears through the alternating signs of the atomic spin populations along the path linking the two magnetic metal centers $5 \mathrm{f}^{2}-5 \mathrm{f}^{2}$ in the BS state, the AF character being mainly explained by spin polarization. 


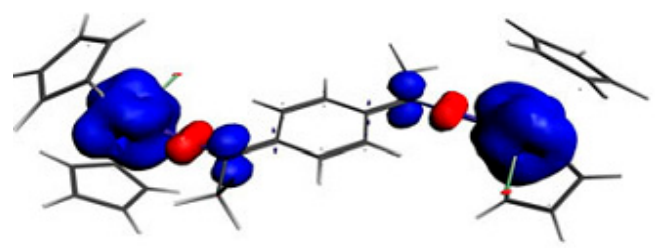

(HS)

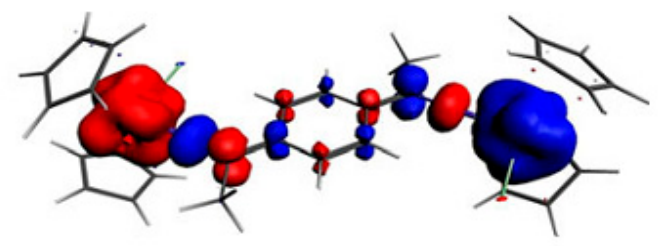

(BS)

(a)

(b)

Figure 15. ZORA/B3LYP spin-density (difference of alpha and beta electron densities) distribution plots for the HS (a) triplet and BS states (b) of $U_{2}$ bis(ketimide) (blue color: positive spin density and red color: negative spin density). (Reprinted with permission from [147], Springer-Verlag, 2012).

The effect of the replacement of one paramagnetic metal $U\left(5 f^{2}\right)$ by the diamagnetic $\operatorname{Th}\left(5 f^{0}\right)$ one in the $\mathrm{U}^{\mathrm{IV}}-(\mu$-ketimide $)-\mathrm{Th}^{\mathrm{IV}}$ hypothetical complex drastically affects the spin polarization effect; the spin densities tend to zero beyond the first neighbors of the paramagnetic center. No magnetic exchange interaction occurs in such a system.

C. C. Cummins and Coll. $[15,16]$ reported in 2013 on the electronic structure and magnetic properties analyses of the arene-bridged $U^{\mathrm{III}} / \mathrm{U}^{\mathrm{III}}$ dimer $\left[\mathrm{U}_{2}\left(\mathrm{~N}\left[{ }^{t} \mathrm{Bu}\right] \mathrm{Ar}\right)_{4}(\mu\right.$-toluene $\left.)\right]\left(\mathrm{Ar}=3,5-\mathrm{C}_{6} \mathrm{H}_{3} \mathrm{Me}_{2}\right)$ complex (Figure 16).

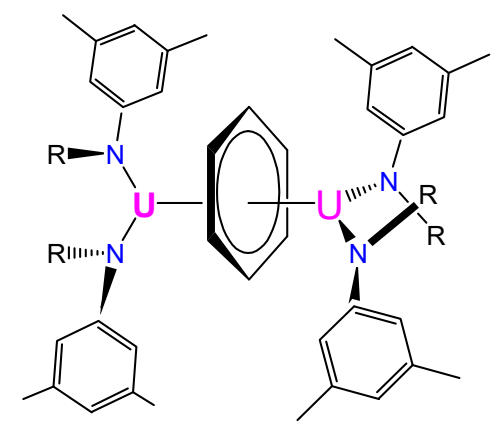

Figure 16. Structure of the ( $\mu$-toluene $) \mathrm{U}_{2}\left(\mathrm{~N}\left[{ }^{\mathrm{t} B u}\right] \mathrm{Ar}\right)_{4}\left(\mathrm{Ar}=3,5-\mathrm{C}_{6} \mathrm{H}_{3} \mathrm{Me}_{2}\right)$ complex [16].

Computationally, DFT geometry optimizations were performed using the Perdew-BurkeErnzerhof (PBE) exchange-correlation functional [148,149] and the dispersion corrected B-97D functional [150] considering a model where the large sized 1-adamantyl and 3,5- $\mathrm{C}_{6} \mathrm{H}_{3} \mathrm{Me}_{2}$ groups were replaced by tbutyl and phenyl moieties, respectively. With reference to the results of DFT and CASSCF/CASPT2 calculations relativistic effects being included with the Douglas-Kroll-Hess (DKH) Hamiltonian (spin-orbit not included), all possible spin states of the model compounds, including singlet, triplet, quintet, and septet spin states, were explored. The DFT electronic structure analysis showed that the highest four SOMOs are $5 \mathrm{f}$ orbitals of the two uranium centers, followed energetically by two covalent $\delta$ MOs, as presented in Figure 17. These latter MOs corresponding to the U-arene-U bonding contain contributions from uranium $5 \mathrm{f}$ orbitals overlapping with $\pi$ antibonding orbitals of the tolyl group. 


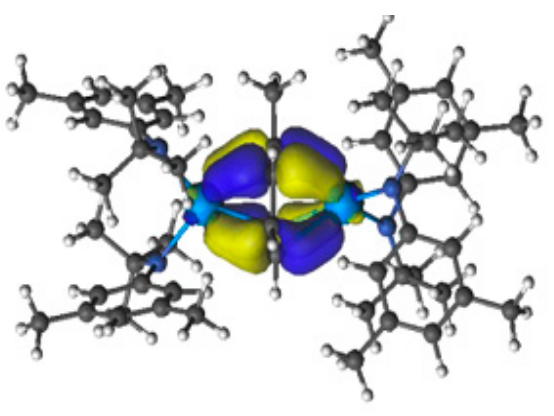

(a)

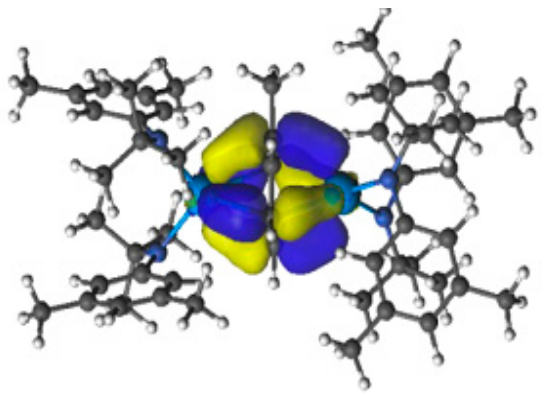

(b)

Figure 17. Singly occupied $\delta$ bonding natural MOs from the ( $\mu$-toluene) $\mathrm{U}_{2}\left(\mathrm{~N}\left[{ }^{\mathrm{t}} \mathrm{Bu}\right] \mathrm{Ar}\right)_{4}$ complex in its quintet state. (a) SOMO-4 and (b) SOMO-5 (reprinted with permission from [16], American Chemical Society, 2013).

The ground state at the CASPT2 level is the singlet; however, the triplet and quintet are respectively 0.7 and $2.5 \mathrm{kcal} / \mathrm{mol}$ higher in energy than the singlet state, whereas the septet is much higher, at $34.5 \mathrm{kcal} / \mathrm{mol}$. As reported by the authors [16], solid-state magnetic susceptibility measurements of the dinuclear system showed complicated features. Indeed, although paramagnetic behavior is observed over the temperature intervals $5-300 \mathrm{~K}$, the 1 / $\chi$ versus $T$ graph showed minimum values between 95 and $125 \mathrm{~K}$, which is characteristic of a transition to AF state. However, the optical and magnetic properties of $\mathrm{U}^{\mathrm{III}}$-( $\mu$-toluene)-UIII were difficult to relate to reported examples of mononuclear uranium organometallic complexes. The authors did not estimate the coupling constants.

As indicated above, remarkable classes of diuranium $(\mathrm{V})$ bridged-oxo complexes exhibiting $\mathrm{UV}^{V} \mathrm{O}_{2}{ }^{+} \ldots \mathrm{UV}^{\mathrm{V}} \mathrm{O}_{2}{ }^{+} \mathrm{CCI}$ and strong $\mathrm{AF}$ exchange coupling were reported by various authors [23-32,46-51, $61,69,114-116]$, motivating theoretical investigations $[7,8,63-65,71,72,74,75,79]$. Among them, strongly coupled binuclear complexes $\left[\mathrm{UO}_{2}\left\{\mathrm{~N}\left(\mathrm{SiR}_{3}\right)_{2}\right\}_{2}(\mathrm{py})_{2}\right]$ forming a butterfly-shaped $\mathrm{Si}-\mathrm{OUO}_{2} \mathrm{UO}-\mathrm{Si}$ uranium(V)-oxo motif (Figure 18) have been synthesized (2012), X-ray characterized and their electronic and magnetic properties investigated with the support of DFT computations [49]. A variable-temperature measurement of susceptibility shows a clear signature of AF coupling between the $5 \mathrm{f}^{1}-5 \mathrm{f}^{1}$ centers.

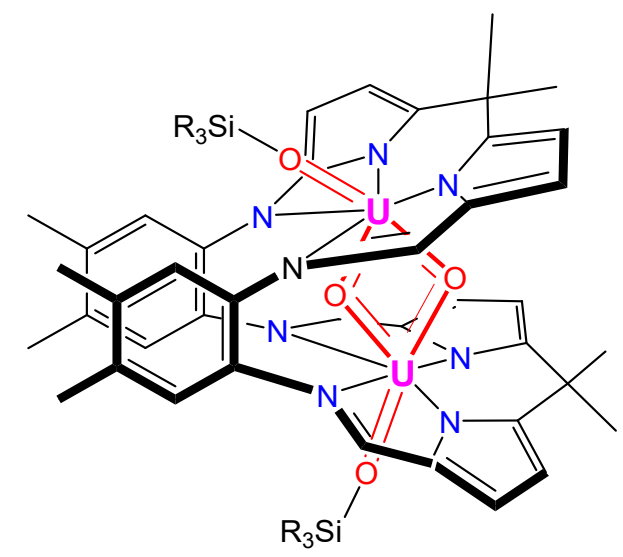

Figure 18. Structure of the butterfly-shaped diuranium(V) $\left[\mathrm{UO}_{2}\left\{\mathrm{~N}\left(\mathrm{SiR}_{3}\right)_{2}\right\}_{2}(\mathrm{py})_{2}\right]$ complex [49].

The geometries of the $5 \mathrm{f}^{1}-5 \mathrm{f}^{1}$ structures were optimized in the gas phase using B3LYP calculations, considering the ferromagnetic triplet $\left(f^{\alpha} f^{\alpha}\right)$, the BS $\left(f^{\alpha} f^{\beta}\right)$ and the spin restricted singlet $\left(f^{\alpha \beta}\right)$ states. A striking structural feature of the $\mathrm{U}_{2} \mathrm{O}_{2}$ core is its $\mathrm{C}_{2 \mathrm{v}}$-symmetrical diamond shape and an average U-O distance of $2.094 \AA$, with a very short U...U separation of 3.3557(5) $\AA$. As reported by the authors using B3LYP calculations [49], the BS state was calculated to be more stable than the triplet and restricted singlet states by 1.4 and $42.7 \mathrm{kcal} / \mathrm{mol}$, respectively, which is in agreement with the 
observed AF character of the complex. The U...U separation was calculated to be equal to 3.366 and $3.379 \AA$ in the $\mathrm{BS}$ and triplet states, respectively, within $0.01 \AA$ deviations from the experimental values. $\mathrm{NBO}$ analysis of the bonding in the $\mathrm{U}_{2} \mathrm{O}_{2}$ core for both states, based on the calculated Mayer and Wiberg bond orders, reveals formally $\mathrm{U}-\mathrm{O}$ single and partially double-bond character, which is in agreement with the structural features. The MO analysis shows that the two $\alpha$ and $\beta$ components of HOMO-27 and HOMO-28, obtained with the B3LYP functional for the BS state, are related to the $\sigma$ and $\pi$ bonding interactions, respectively, within the $\mathrm{U}_{2} \mathrm{O}_{2}$ core. The $\pi$-type orbitals, which are dominated by $2 \mathrm{p}$-contributions from the oxo-bridged atoms, appear to stabilize the diamond $\mathrm{U}_{2} \mathrm{O}_{2}$ core. The B3LYP calculated spin density in the AF BS state shows the $\mathrm{f}^{\alpha} \mathrm{f}^{\beta}$ configuration with electrons of different spins localized on each uranium atom.

As reported in the same study [49], the calculated U...U separation of $3.366 \AA$ is much shorter than twice the covalent radius of the uranium atom (3.92 $\AA$ ), which may indicate some metal-metal bonding interaction, as predicted by theory [145,151-154]. However, the structural analogy with $\mathrm{Mo}^{\mathrm{V}}(\mu-\mathrm{O}){ }_{2} \mathrm{Mo}^{\mathrm{V}}$ complexes which exhibit single Mo-Mo bonds was faced to the paramagnetic state of the $\mathrm{U}^{\mathrm{V}}(\mu-\mathrm{O})_{2} \mathrm{U}^{\mathrm{V}}$ complex, and no reported examples exist of molecular bonds between two f-block ions in such structures. The authors conclude that the extremely short $\mathrm{U}$...U separation exhibited by the diuranium $(\mathrm{V})$ oxo-bridged system indicates strong electronic communication between the two $5 \mathrm{f}^{1}$ centers. However, it was postulated that the geometry of the oxo-group interaction within the diamond-shaped $\mathrm{U}_{2} \mathrm{O}_{2}$ core, and not the shortened $\mathrm{U} \cdots \mathrm{U}$ separation, was the primary mediator of the super-exchange. Indeed, as reported by the authors, ${ }^{20 \mathrm{~d}}$ the AF coupling due to super-exchange across the two oxo groups, modeled by a spin Hamiltonian, led to a particularly large fitted value $J_{\text {exp }}=-33 \mathrm{~cm}^{-1}$, suggesting that the butterfly geometry could be of interest for the building more complex magnetic structures.

Other diuranium bis( $\mu$-oxo) systems, synthesized by K. Meyer and Coll. [115], (in 2014) exhibit diamond-core shaped $\left[\mathrm{U}(\mu-\mathrm{O})_{2} \mathrm{U}\right]$ structural motifs and remarkably different magnetic behaviors depending on the uranium oxidation state. Indeed, the magnetic data show for pentavalent $\left[\left\{\left(\left({ }^{\mathrm{nP}, \mathrm{Me}} \mathrm{ArO}\right)_{3} \operatorname{tacn}\right) \mathrm{U}^{\mathrm{V}}\right\}_{2}(\mu-\mathrm{O})_{2}\right]\left(\operatorname{tacn}=\right.$ triazacyclononane, $\mathrm{nP}=$ neopentyl) structure a $\mathrm{U}^{\mathrm{V}} / \mathrm{U}^{\mathrm{V}} \mathrm{AF}$ coupled system, while its reduced species, the dianionc $\left.\mathrm{U}^{\mathrm{IV}} / \mathrm{U}^{\mathrm{IV}} \mathrm{K}_{2}\left[\left\{\left({ }^{2}, \mathrm{Me} A r O\right){ }_{3} \operatorname{tacn}\right) \mathrm{U}^{\mathrm{IV}}\right\}_{2}(\mu-\mathrm{O})_{2}\right]$ tetravalent complex, revealed itself to be non-magnetic [115]. These two complexes (Figure 19), have been investigated computationally using B3LYP coupled to the BS approach; scalar relativistic effects were accounted for by using the ZORA Hamiltonian [155].

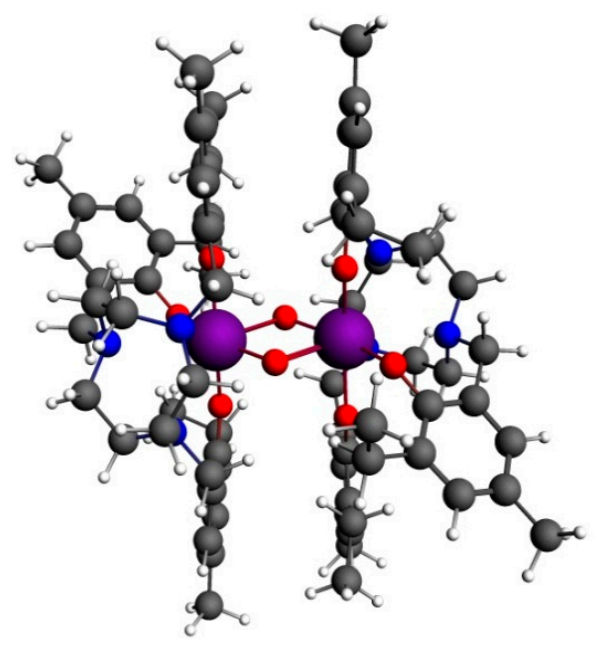

(a)

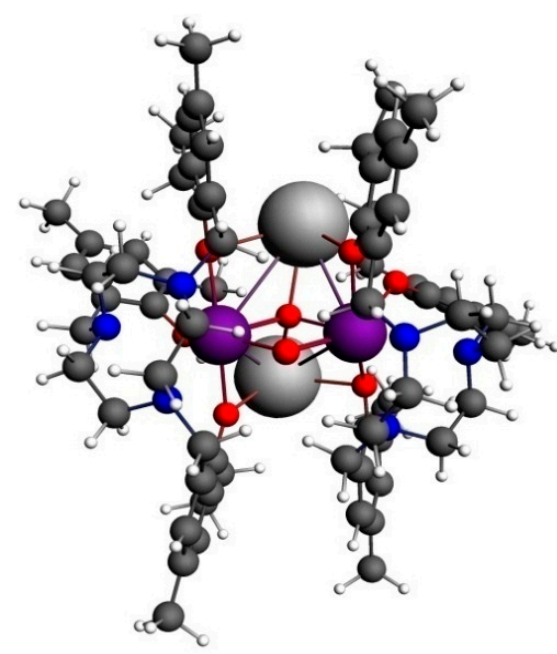

(b)

Figure 19. Optimized molecular structures of the $(\mathbf{a})\left[\mathrm{U}^{\mathrm{V}}(\mu-\mathrm{O})_{2} \mathrm{U}^{\mathrm{V}}\right]$ and $(\mathbf{b}) \mathrm{K}_{2}\left[\mathrm{U}^{\mathrm{IV}}(\mu-\mathrm{O})_{2} \mathrm{U}^{\mathrm{IV}}\right]$ complexes (reprinted with permission from [155], American Chemical Society, 2016). 
The computations reveal the BS ground state of the pentavalent $\left[\mathrm{U}^{\mathrm{V}}(\mu-\mathrm{O})_{2} \mathrm{UV}^{\mathrm{V}}\right] 5 \mathrm{f}^{1}-5 \mathrm{f}^{1}$ complex lower in energy than the high spin (HS) triplet state, indicating a AF character in agreement with experimental magnetic susceptibility measurements. The non-magnetic character observed for the tetravalent $\mathrm{K}_{2}\left[\mathrm{U}^{\mathrm{IV}}(\mu-\mathrm{O})_{2} \mathrm{U}^{\mathrm{IV}}\right] 5 \mathrm{f}^{2} / 5 \mathrm{f}^{2}$ species is also predicted by ZORA/B3LYP calculations which led practically to the same energy for the HS and BS states [115]. As previously reported for related dioxo diuranium(V) systems [49], super-exchange is likely to be responsible for the AF coupling through the $\pi$-network orbital pathway within the $(\mu-\mathrm{O})_{2}$ bridge, with the dissymmetrical structure of the $\mathrm{U}_{2} \mathrm{O}_{2}$ core playing a determining role. Spin densities in HS and BS states were computed for the $\mathrm{U}^{\mathrm{V}}(\mu-\mathrm{O})_{2} \mathrm{UV}^{\mathrm{V}}$ complex in order to understand and rationalize their AF character. The obtained spin density surfaces (Figure 20) showed that both HS and BS states exhibit localized spin densities on the two magnetic diuranium $(V)$ centers, with significant values on their nearest $\mathrm{O}_{\text {oxo }}$ and non-negligible ones on the $\mathrm{O}_{\text {Ar }}$ neighbors.

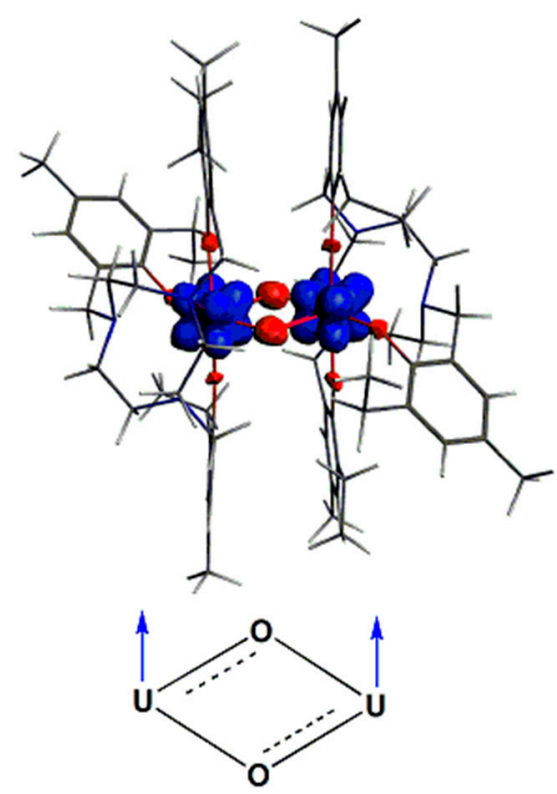

(a)

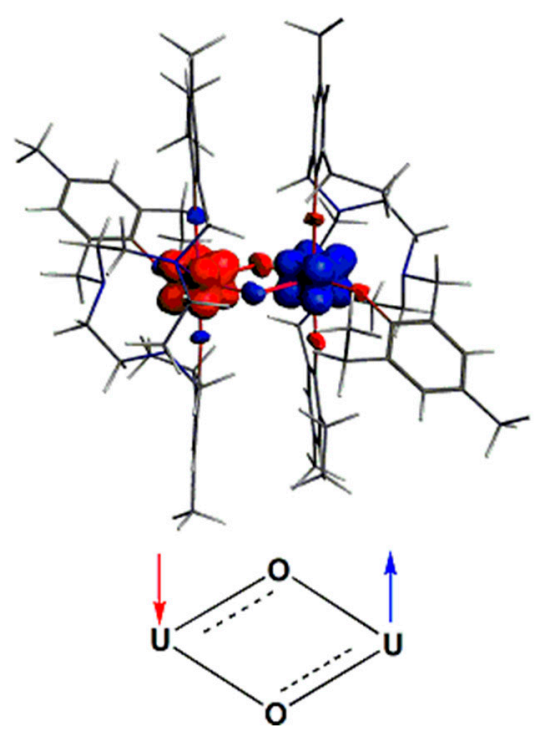

(b)

Figure 20. ZORA/B3LYP spin density surfaces for the HS (triplet) in left and BS states in right of $\mathrm{U}^{\mathrm{V}}(\mu-\mathrm{O})_{2} \mathrm{U}^{\mathrm{V}}$ complex (blue color: positive and red color: negative spin density). The plotted isodensity surfaces (a) HS and (b) BS states corresponds to a value of $\pm 0.0025 \mathrm{e} \mathrm{bohr}^{-3}$. (reprinted with permission from [155], American Chemical Society, 2016).

Interestingly, the spin density maps show that the difference between the HS and BS states is the sign alternation of the spin populations around the dioxo $(\mu-\mathrm{O})_{2}$ path-linking the two magnetic $\mathrm{U}^{\mathrm{V}}\left(5 \mathrm{f}_{\mathrm{xyz}}{ }^{1}\right)$ centers in its BS state. For the HS state, the spin of the bridging $(\mu-\mathrm{O})_{2}$ ligands is symmetrically polarized by the two $\mathrm{U}^{\mathrm{V}}$ spin carriers. In contrast, for the BS state, the two oxygen atoms are differently polarized with sign alternation of positive and negative spin densities.

The magnetic properties of di- and triuranyl $(\mathrm{V})\left[\mathrm{UO}_{2}(\mathrm{dbm})_{2} \mathrm{~K}(18 \mathrm{C} 6)\right]_{2}(\mathrm{dbm}$ : dibenzoylmethanate) and $\left[\mathrm{UO}_{2}(\mathrm{~L})\right]_{3}(\mathrm{~L}=2$ (4-Tolyl)-1,3-bis(quinolyl)malondiiminate) complexes (Figure 21), exhibiting diamond-shape $\mathrm{U}_{2} \mathrm{O}_{2}$ and triangular-shape $\mathrm{U}_{3} \mathrm{O}_{3}$ cores with $5 \mathrm{f}^{1}-5 \mathrm{f}^{1}$ and $5 \mathrm{f}^{1}-5 \mathrm{f}^{1}-5 \mathrm{f}^{1}$ configurations, have been studied experimentally [23-25]. The ZORA/B3LYP calculations (unpublished results) which have been carried out confirm the AF character of these complexes. The estimated $J$ values have been respectively found equal to -24.1 and $-7.2 \mathrm{~cm}^{-1}$ for the dioxo and the trioxo species, the used geometries of the magnetic cores being those of the $\mathrm{X}$-ray structures. 


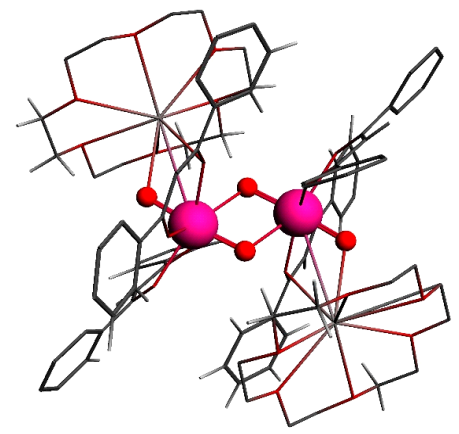

(a)

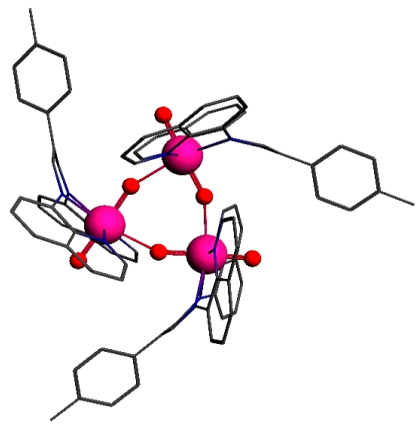

(b)

Figure 21. Optimized molecular structures of dioxo (a) $\left[\mathrm{UO}_{2}(\mathrm{dbm})_{2} \mathrm{~K}(18 \mathrm{C} 6)\right]_{2}$ and trioxo (b). $\left[\mathrm{UO}_{2}(\mathrm{~L})\right]_{3}$ ( $\mathrm{L}=2$ (4-Tolyl)-1,3-bis(quinolyl)malondiiminate) Sticks used to depict $\mathrm{C}, \mathrm{N}$ and $\mathrm{K}$ atoms; $\mathrm{H}$ atoms have been omitted for clarity. Pink and red colors respectively for uranium and oxygen atoms. (Unpublished results).

The obtained spin density maps (difference between the $\alpha$ and $\beta$ electron densities) of the HS and BS states of the diuranyl species are displayed in Figure 22. They are rather similar to those of the $\mathrm{U}^{\mathrm{V}}(\mu-\mathrm{O})_{2} \mathrm{U}^{\mathrm{V}}$ complex (Figure 20).

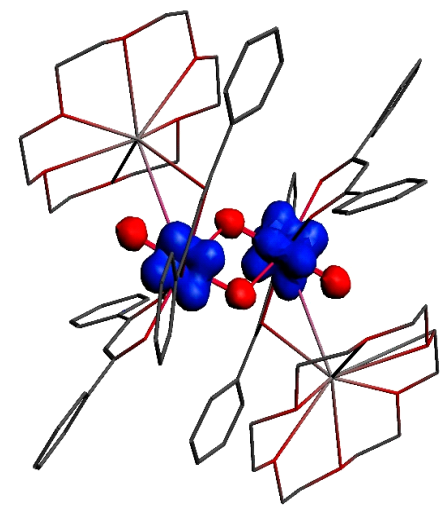

(a)

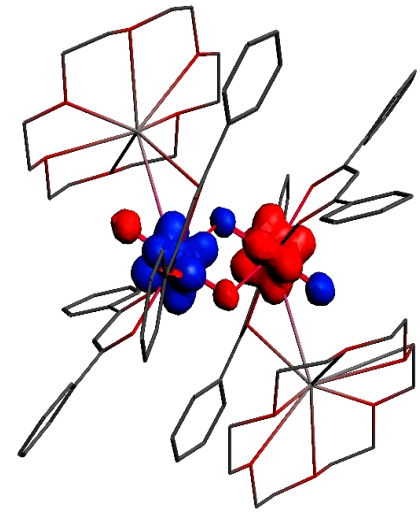

(b)

Figure 22. ZORA/B3LYP spin density distributions for the HS (triplet) and BS states of the dioxo $\left[\mathrm{UO}_{2}(\mathrm{dbm})_{2} \mathrm{~K}(18 \mathrm{C} 6)\right]_{2}$ system (blue color: positive and red color: negative spin density). The isodensity surface corresponds to a value of $0.0025 \mathrm{e} \mathrm{bohr}^{-3}$. (Unpublished results). (a) (HS); (b) (BS).

More recently (2017), the first benzoquinonoid-bridged dinuclear actinide complexes were reported by S. Hohloch et al. [156] The target dinuclear systems with different structures, i.e., $\mathrm{UI}(\mathrm{L})]_{2},[\mathrm{Th}(\mathrm{L})]_{2} \mathrm{Q}^{\mathrm{Dipp}},[\mathrm{Th}(\mathrm{THF})(\mathrm{L})]_{2} \mathrm{Q}^{\mathrm{OMe}}$ and $[\mathrm{U}(\mathrm{L})]_{2} \mathrm{Q}^{\mathrm{OMe}}$ associated with the tripodal tris[2-amido(2-pyridyl)ethyl]amine ligand $\mathrm{L}$, have been synthesized from the dianionic 2,5-bis [2,6-(diisopropyl)anilide]-1,4-benzoquinone $\left(\mathrm{Q}^{\text {Dipp}}\right)$ and 2,5-bis[2-(methoxy)anilide]-1,4-benzoquinone $\left(\mathrm{Q}^{\mathrm{OMe}}\right)$ ligands, as depicted for the quinoid-bridged $\mathrm{U}^{\mathrm{IV}} / \mathrm{U}^{\mathrm{IV}}$ diuranium system in Figure 23. 


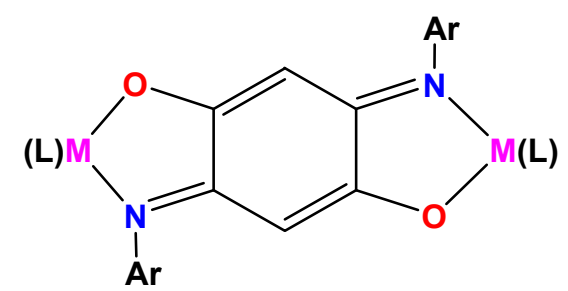

(a)

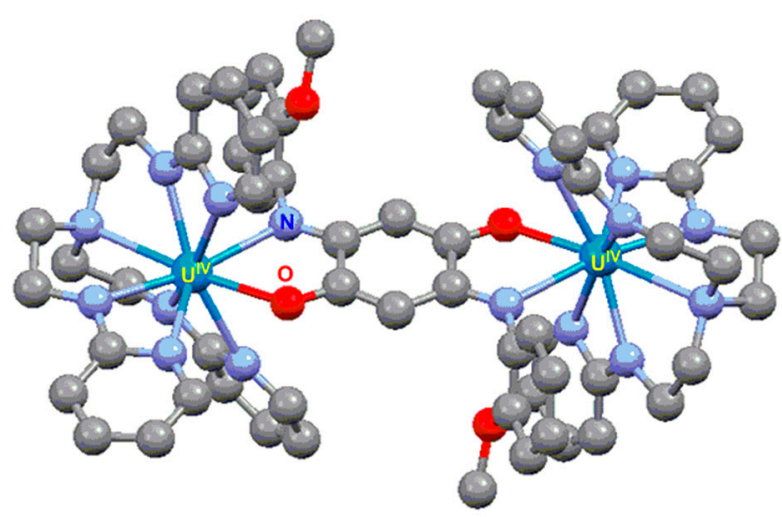

(b)

Figure 23. Schematic depiction (a) and molecular structure (b) of the imino-alkoxy quinoid diuranium(IV) $[\mathrm{U}(\mathrm{L})]_{2} \mathrm{Q}^{\mathrm{OMe}}$ system. (reprinted with permission from [156], the Royal Society of Chemistry, 2017).

As reported by the authors, magnetic measurements of the duranium(IV) iodide [UI(L) $]_{2}$ and quinoid $[\mathrm{U}(\mathrm{L})]_{2} \mathrm{Q}^{\mathrm{OMe}}$ bridged species, which exhibit long intermetallic $\mathrm{U}^{\mathrm{IV}} \ldots \mathrm{U}^{\mathrm{IV}}$ distances i.e., 5.125(1) ̊ and 8.904(1) ̊ respectively, indicate that there is weak magnetic exchange between the two uranium(IV) ions which was not quantified from the DC susceptibility measurements. Furthermore, as reported in the study, the low-temperature susceptibility data indicate that the ground states for the two $\mathrm{U}^{\mathrm{IV}} / \mathrm{U}^{\mathrm{IV}}$ dimer should be non-magnetic singlets. With the support of DFT calculations, using a hybrid B3PW91 functional [157] and a core pseudopotential for uranium, the electronic structure analysis of the $\mathrm{U}^{\mathrm{IV}} / \mathrm{U}^{\mathrm{IV}}$ diuranium $[\mathrm{U}(\mathrm{L})]_{2} \mathrm{Q}^{\mathrm{OMe}}$ system shows that the four unpaired electrons occupying SOMOs, are mainly of mixed uranium/quinoid character as illustrated by the SOMO-2 (Figure 24), except the SOMO-1, which is purely metal-based.

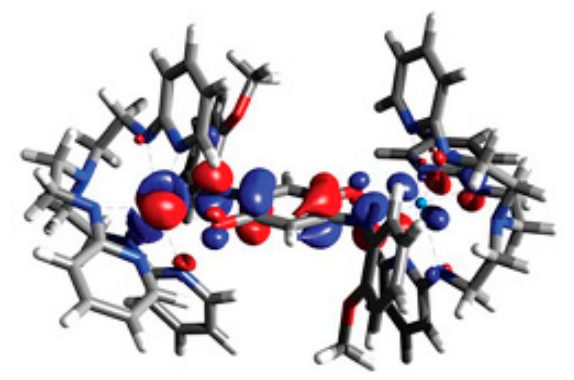

Figure 24. SOMO-2 of the $[\mathrm{U}(\mathrm{L})]_{2} \mathrm{Q}^{\mathrm{OMe}}$ quintet state system. Plot surfaces displayed with an iso-value of 0.02 au (reprinted with permission from [156], the Royal Society of Chemistry, 2017).

The unpaired spin-density plot (Figure 25) shows that there is significant spin-delocalisation from uranium to the quinoid bridge.

Importantly, the quinoid ligand of the diuranium(IV) $[\mathrm{U}(\mathrm{L})]_{2} \mathrm{Q}^{\mathrm{OMe}}$ complex could undergo a reversible reduction to form a radical anion. However, the chemical redox reaction leads to an unstable and sensitive anionic complex, despite the fact that X-ray crystallography indicates that the product contains a radical bridge. However, the magnetometry of the anionic species has not been investigated, and the impact of the radical bridge on the intermetallic exchange interaction could not be evaluated. 


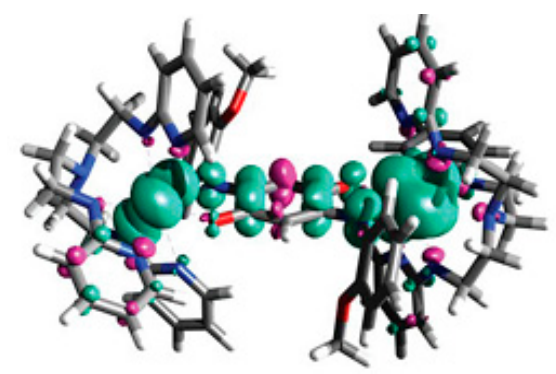

Figure 25. spin-density plot of the $[\mathrm{U}(\mathrm{L})]_{2} \mathrm{Q}^{\mathrm{OMe}}$. Plot surfaces displayed with an iso-value of $0.02 \mathrm{au}$ (reprinted with permission from [156], the Royal Society of Chemistry, 2017).

\subsection{Mononuclear Actinide Complexes}

Several uranium-radical systems emerged in the mid-2000s as mononuclear complexes exhibiting magnetic properties [62,66,74,129-131,158-170]. Structural, spectroscopic and magnetic properties of various mononuclear uranium(IV)-benzophenone radical complexes; e.g., the ketyl $\left[\left({ }^{\mathrm{BBu}} \mathrm{ArO}\right)_{3}\right.$ tacn) $\left.\mathrm{U}^{\mathrm{IV}}\left(\mathrm{OC} \cdot{ }^{\mathrm{ABu}} \mathrm{Ph}_{2}\right)\right]$ complex (2) (Figure 26), were investigated by O.P. Lam et al. (2008) [164] with the support of DFT calculations. The temperature dependence of the magnetic susceptibility data for this ketyl radical complex shows a similar trend to that of a previous $\mathrm{CO}_{2}$ $\eta^{1}$-bound uranium $\left.\left[\left({ }^{\mathrm{Ad}} \mathrm{ArO}\right)_{3} \operatorname{tacn}\right) \mathrm{U}^{\mathrm{IV}}\left(\mathrm{CO}_{2}{ }^{\bullet-}\right)\right]$ complex [165].

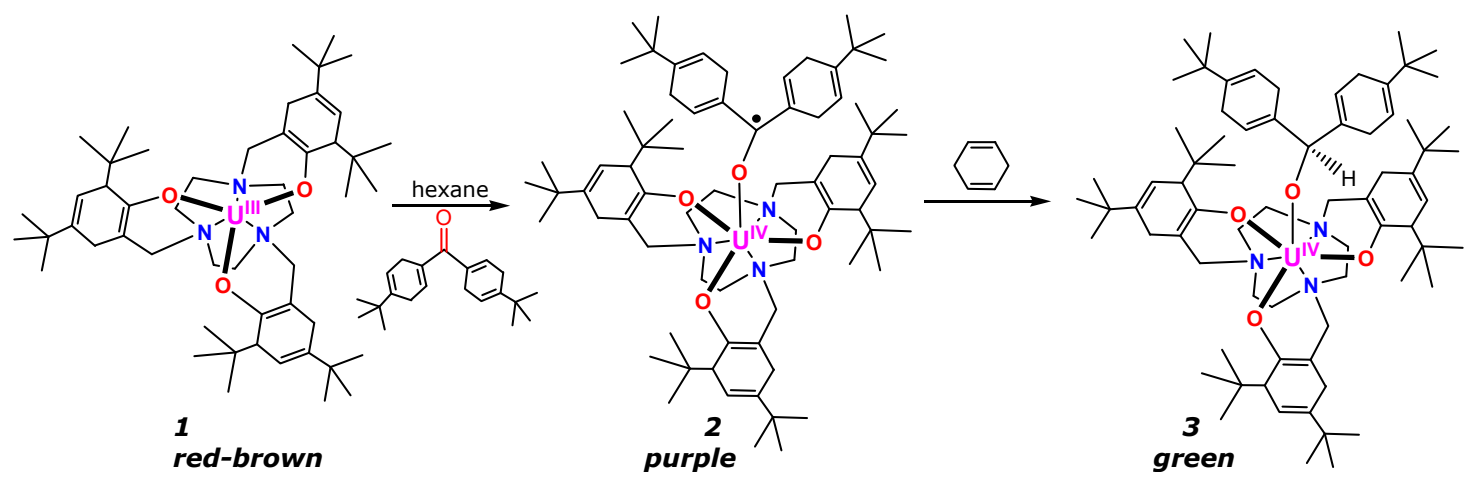

Figure 26. Formation of U(IV) benzophenone ketyl radical complex 2 through a one-electron reduction of 4,4'-Di-tert-butylbenzophenone by U(III) precursor complex [((t-BuArO) ${ }_{3}$ tacn) $\left.\mathrm{U}^{\mathrm{III}}\right]$ (1) followed by $\mathrm{H}$ abstraction to form a U(IV) diphenyl methoxide complex 3 [164].

The ketyl radical complex 2 was modeled to have three unpaired electrons, computing it as a $\mathrm{U}(\mathrm{III})$ complex. However, the resulting orbitals and spin density plots (Figure 27) suggest a more complex representation.

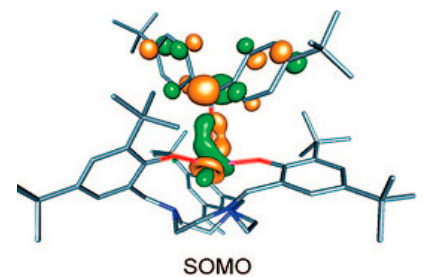

(a)

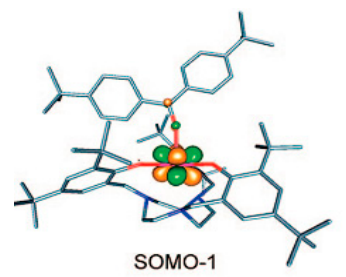

(b)

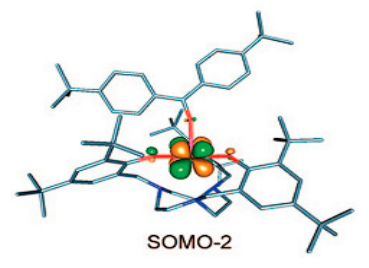

(c)

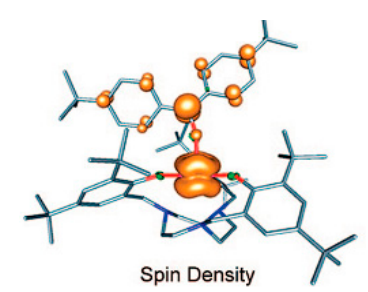

(d)

Figure 27. DFT isosurface contour plots featuring frontier SOMOs and spin density of the ketyl $\left[\left({ }^{\mathrm{tBu}} \mathrm{ArO}\right)_{3}\right.$ tacn $\left.) \mathrm{U}^{\mathrm{IV}}\left(\mathrm{OC} \cdot{ }^{\mathrm{tBu}} \mathrm{Ph}_{2}\right)\right]$ complex (2). (a) SOMO; (b) SOMO-1; (c) SOMO-2; (d) Spin density. (Reprinted with permission from [164], American Chemical Society, 2008.) 
As reported by the authors, while SOMO-2 and SOMO- 1 (Figure 27) are of $\delta$-type $\mathrm{f}_{\mathrm{xyz}}$ and $\mathrm{f}_{\mathrm{z}(\mathrm{x} 2 \mathrm{-y} 2)}$ pure uranium $5 \mathrm{f}$ orbitals, the highest energy SOMO exhibits a metal/ligand character. The resulting spin density of the $U(I V) 5 f^{2}$ complex (2) confirms that the $f_{x y z}$ and $f_{z(x 2-y 2)}$ orbitals carry the main part of the spin, with a small spin polarization on the coordinated ligand. Variable temperature magnetization data were measured for two independently synthesized samples. The data of complex (2) show a steady drop in $\mu_{\text {eff }}$ as the temperature is lowered, decreasing from $3.48 \mu_{\mathrm{B}}$ at $300 \mathrm{~K}$ to $1.61 \mu \mathrm{B}$ at $5 \mathrm{~K}$ which is unusual compared to common $\mathrm{U}(\mathrm{IV})\left(5 \mathrm{f}^{2}\right)$ complexes and is likely due to magnetic contributions from the unpaired electron residing on the disubstituted benzophenone fragment, as well as from the U(III) resonance structure (Figure 28, 2d). This is consistent with the DFT calculations, in which one third of the single radical electron is localized on the uranium, hence, increasing the magnetic moment.

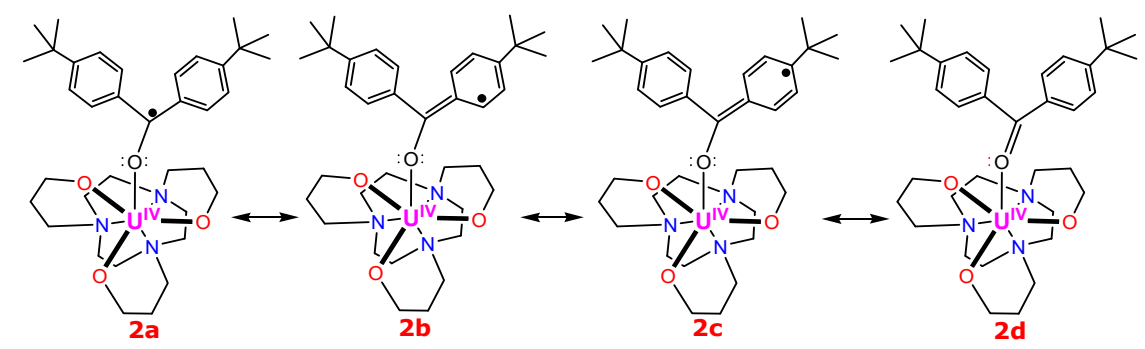

Figure 28. Resonance structures of complex 2 (labelled 2a-2d) [164].

The authors concluded that regarding the magnetic data of complex (2) revealing an unusual $\mathrm{U}(\mathrm{IV}) 5 \mathrm{f}^{2}$ complex which should be considered as a charge-separated $\mathrm{U}(\mathrm{III})-\mathrm{L} \leftrightarrow \mathrm{U}(\mathrm{IV})-\mathrm{L}^{\bullet-}\left(5 \mathrm{f}^{3}\right) \leftrightarrow$ $\left(5 f^{2}\right)$ species. DFT calculations suggest that coupling between the $\mathrm{U}^{\mathrm{IV}}$ center and the ketyl radical $\mathrm{L}^{\bullet-}$ ligand is at least physically reasonable because the computed frontier SOMO of the molecule possesses both metal and ligand contribution.

\subsection{Mixed Actinide/Transition Metal (5f-3d) and Actinide/Lanthanide (5f-4f) Complexes}

To date, only scarce examples of mixed ( $5 \mathrm{f}-3 \mathrm{~d}$ ) actinide/transition metal complexes exhibiting magnetic exchange interactions are found in the literature $[1,43-45,114,115,118-121]$. Moderate ferromagnetic exchange coupling was measured by J. D. Rinehart et al. (2007) [1,122] for the linear chloride-bridged $5 \mathrm{f}-3 \mathrm{~d}$ heterometallic mixed trinuclear $\mathrm{U}^{\mathrm{IV}} / \mathrm{M}^{\mathrm{II}} / \mathrm{U}^{\mathrm{IV}}$ dimethylpyrazolate (cyclam) $\mathrm{M}^{\mathrm{II}}\left[(\mu-\mathrm{Cl}) \mathrm{U}^{\mathrm{IV}}\left(\mathrm{Me}_{2} \mathrm{Pz}\right)_{4}\right]_{2}\left(\mathrm{M}^{\mathrm{II}}=\mathrm{Ni}, \mathrm{Cu}, \mathrm{Co}, \mathrm{Zn}\right)$ cluster shown in Figure 29.

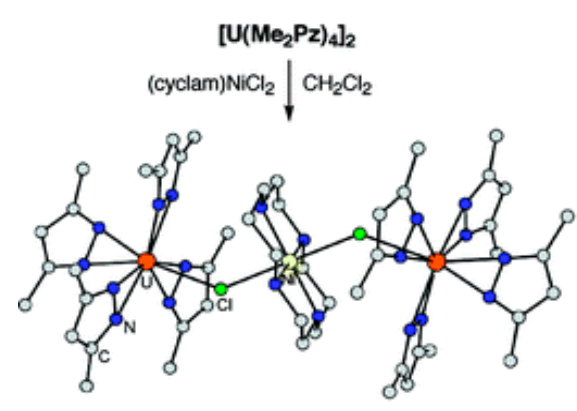

(a)

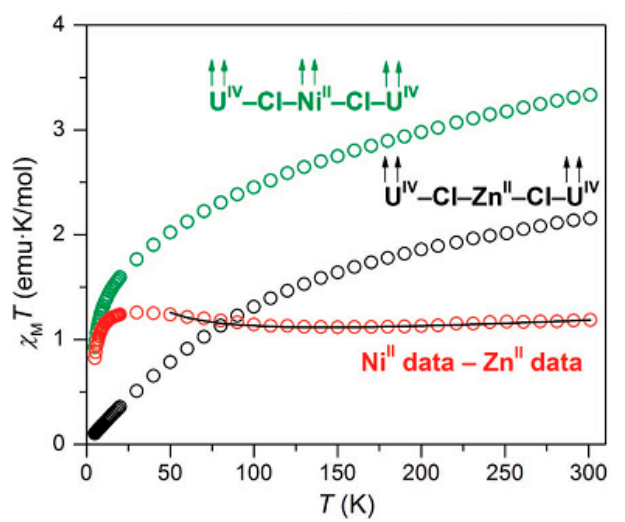

(b)

Figure 29. (a) Structure of the linear cluster (cyclam) $\mathrm{Co}^{\mathrm{II}}\left[(\mu-\mathrm{Cl}) \mathrm{U}^{\mathrm{IV}}\left(\mathrm{Me}_{2} \mathrm{Pz}\right)_{4}\right]_{2}$ and (b) Variabletemperature magnetic susceptibility plot. Orange, purple, green, gray, and blue spheres represent $\mathrm{U}, \mathrm{Co}, \mathrm{Cl}, \mathrm{C}$, and $\mathrm{N}$ atoms, respectively. $\mathrm{H}$ atoms are omitted for clarity (reprinted with permission from [122], American Chemical Society, 2007). 
The measured exchange constant $\mathrm{J}$ lies in the range $15-48 \mathrm{~cm}^{-1}$ for the $\mathrm{CoU}_{2}$ cluster core and 2.8-19 $\mathrm{cm}^{-1}$ for the $\mathrm{NiU}_{2}$ congener. To understand the origin of this ferromagnetic coupling within the $\mathrm{MU}_{2}$ core, the authors considered a spin Hamiltonian of the following form: $\hat{\mathrm{H}}=-2 \mathrm{~J}\left[\hat{\mathrm{S}}_{\mathrm{Co}} \cdot\left(\hat{\mathrm{S}}_{\mathrm{U} 1}+\hat{\mathrm{S}}_{\mathrm{U} 2}\right)\right]$.

$\mathrm{DFT} / \mathrm{PBE}$ calculations which were performed [58] on a $\left[\left(\mathrm{Me}_{2} \mathrm{Pz}\right)_{4} \mathrm{UCl}\right]^{-}$anionic fragment of the cluster revealed the unpaired electrons of the $\mathrm{U}^{\mathrm{IV}}$ center to reside in the $5 \mathrm{f}_{\mathrm{xyz}}$ and $5 \mathrm{f}_{\mathrm{z}\left(\mathrm{x}^{2}-\mathrm{y}^{2}\right)}$ orbitals, as shown in Figure 30 [122].

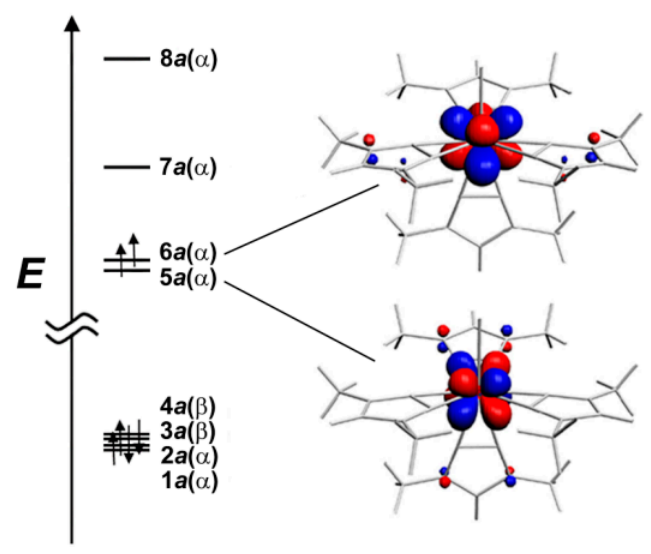

Figure 30. DFT frontier energy level diagram and MOs for $\left[\left(\mathrm{Me}_{2} \mathrm{Pz}\right)_{4} \mathrm{UCl}\right]^{-}$. The $\mathrm{Me}_{2} \mathrm{Pz}$ - ligands are shown as skeletal representations, and the $\mathrm{U}-\mathrm{Cl}$ axis is oriented vertically (reprinted with permission from [122], American Chemical Society, 2007).

As reported, these orbitals have $\delta$ symmetry with respect to the $\mathrm{U}-\mathrm{Cl}$ z-axis bond, such that the overlap with $\sigma$ and $\pi$ orbitals of the chloride bridge will be zero. Any of the spin from the $\mathrm{Co}^{\mathrm{II}} 3 \mathrm{dz}^{2}$ orbital feeding through the chloride bridging ligands will therefore engage rigorously orthogonal orbitals, leading to a ferromagnetic exchange interaction. Consistently, ferromagnetic exchange is also observed for the $\mathrm{NiU}_{2}$ cluster, which features a Ni${ }^{\mathrm{II}}(\mathrm{S}=1)$ center with unpaired electrons in the $3 \mathrm{~d}_{\mathrm{z} 2}$ and $3 d_{x 2-y_{2}}$ orbitals. However, despite the presence of a large axial zero-field splitting for $\mathrm{NiU}_{2}$, no indication of the slow magnetic relaxation is reported, as is typically observed for SMM behavior [1].

During the same year (2007) there has been a report suggesting that coupling may occur through direct metal-metal orbital overlap in the mixed-valence linear trinuclear cluster $\mathrm{U}\left(\mathrm{fc}\left[\mathrm{NSiMe}_{3}\right]_{2}\right)_{2}$ (fc $=1,1^{\prime}$-ferrocenylene) and its $\left[\mathrm{Fe}^{\mathrm{II}} \mathrm{U}^{\mathrm{IV}} \mathrm{Fe}^{\mathrm{III}}\left(\mathrm{C}_{5} \mathrm{H}_{4} \mathrm{NSi}\left({ }^{\mathrm{t}} \mathrm{Bu}\right) \mathrm{Me}_{2}\right)_{4}\right] \mathrm{BPh}_{4}$ cationic congener which is depicted in Figures 31 and 32. [18] The latter molecule exhibits a rigid coordination to ferrocenylamido moieties and U...Fe distances of 2.9556(5) and 2.9686(5) A.
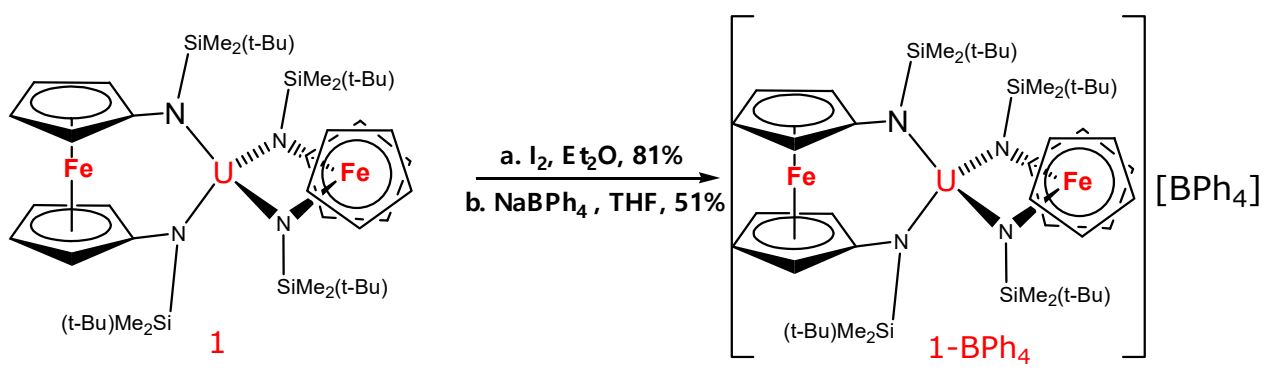

Figure 31. The transformation reaction of $1 \mathrm{U}\left(\mathrm{fc}_{\mathrm{c}}\left[\mathrm{NSiMe}_{3}\right]_{2}\right)_{2}$ into $\left[\mathrm{Fe}^{\mathrm{II}} \mathrm{U}^{\mathrm{IV}} \mathrm{Fe}^{\mathrm{III}}\left(\mathrm{C}_{5} \mathrm{H}_{4} \mathrm{NSi}\left({ }^{\mathrm{t}} \mathrm{Bu}\right)\right.\right.$ $\left.\left.\mathrm{Me}_{2}\right)_{4}\right] \mathrm{BPh}_{4}:$ 1-BPh4 [18]. 


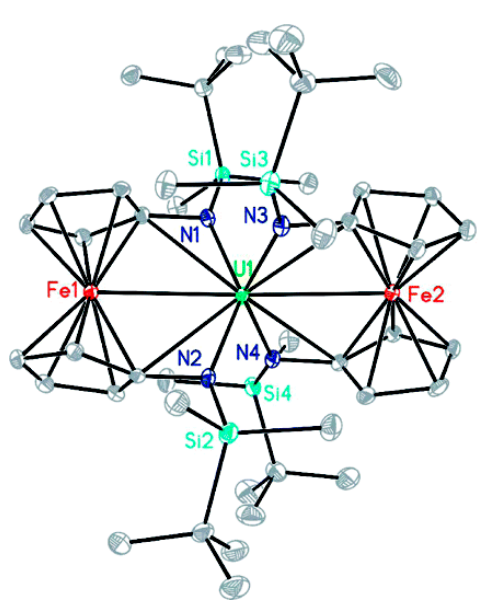

(a)

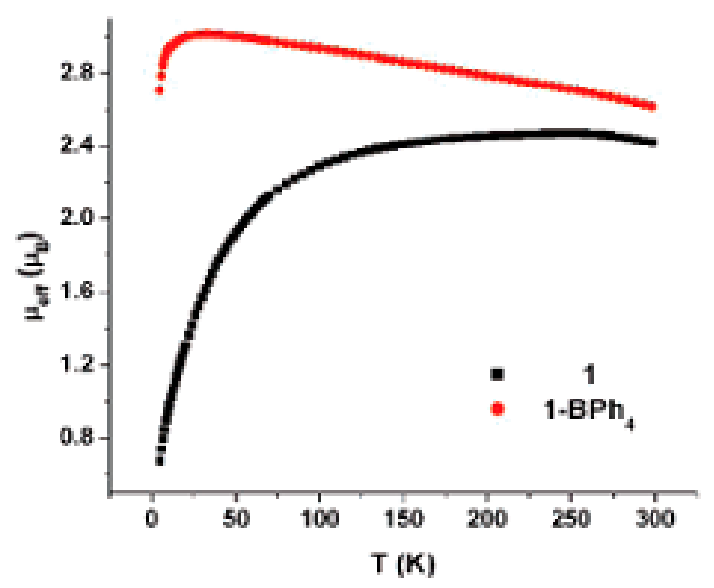

(b)

Figure 32. (a) X-ray Structure of $\left[\mathrm{Fe}^{\mathrm{II}} \mathrm{U}^{\mathrm{IV}} \mathrm{Fe}^{\mathrm{III}}\left(\mathrm{C}_{5} \mathrm{H}_{4} \mathrm{NSi}\left({ }^{\mathrm{t}} \mathrm{Bu}\right) \mathrm{Me}_{2}\right)_{4}\right]$ cation $\left(1^{+}\right)$complex. $\mathrm{H}$ atoms are omitted for clarity. (b) Variable-temperature magnetic data for $\mathrm{UFe}_{2}^{\mathrm{II}} 2$ (1, black squares) and $\mathrm{Fe}^{\mathrm{II}} \mathrm{UV}^{\mathrm{IV}} \mathrm{Fe}^{\mathrm{III}}$ (1-BPh 4 , red circles). (Reprinted with permission from [18], American Chemical Society, 2007).

This mixed-valent bisferrocenyl complexes have been studied in order to understand the dependence of the electronic coupling between the two iron centers relative to the linker connecting them. When uranium is used as a linker, $5 \mathrm{f}$ orbitals make this actinide a better mediator than the zirconium d-transition metal for the electronic communication between iron centers. Indeed, as noted by the authors $[1,18]$, the observed behavior is indicative of an extremely strong ferromagnetic exchange $\mathrm{U}^{\mathrm{IV}}-\mathrm{Fe}^{\mathrm{III}}$ interaction, mediated by direct orbital overlap between the metals orbitals. DFT calculations were performed on the thorium and zirconium bisferrocene trinuclear $\mathrm{Th}\left(\mathrm{fc}[\mathrm{NH}]_{2}\right)_{2}$ cation models related to the actual $\mathrm{U}\left(\mathrm{fc}_{\mathrm{c}}\left[\mathrm{NSiMe}_{3}\right]_{2}\right)_{2}$ system. For the thorium bisferrocene cation model, additionally, the HOMO and HOMO-5 (Figure 33) consist of a uranium $5 \mathrm{f}$ orbital interacting with orbitals of both iron atoms at the same time, which might explain the occurrence of strong electronic communication mediated by actinide-transition metal orbital overlap.

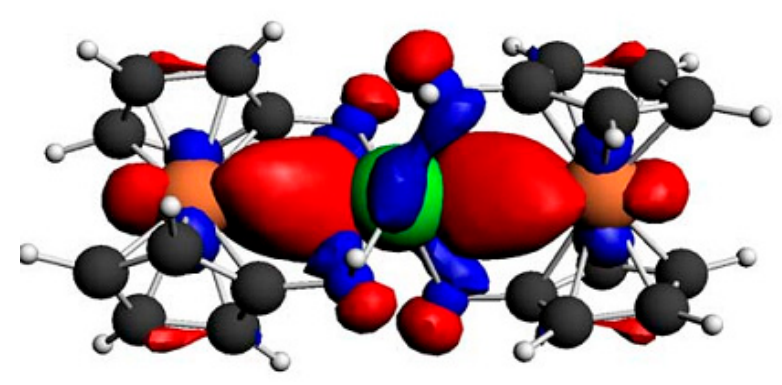

Figure 33. HOMO-5 of the $\mathrm{Th}\left(\mathrm{fc}_{\mathrm{c}}[\mathrm{NH}]_{2}\right)_{2}$ model cation. Green and magenta color for Th and $\mathrm{Zr}$ metals, respectively (reprinted with permission from [18], American Chemical Society, 2007).

Finally, magnetic coupling was also reported in 2006 for $5 \mathrm{f}-4 \mathrm{f}$ trinuclear $\mathrm{UYb}_{2}$ cluster $\mathrm{Cp}_{2}{ }_{2} \mathrm{U}\left[\left(\mathrm{NC}\left(\mathrm{CH}_{2} \mathrm{C}_{6} \mathrm{H}_{5}\right) \mathrm{tpy}\right) \mathrm{YbCp}_{2}\right]_{2}$ (tpy = terpyridyl) [108].

\subsection{Magnetic Susceptibility and EPR/NMR Spectra of Actinide Complexes}

New developments in the computational transuranium chemistry were surveyed recently (2018) by N. Katsoyannis [8], with emphasis on the assessment of the magnetic properties of transuranic elements. As reported in this review, the magnetic susceptibility and the electronic structure of borate materials, in particular those of Californium (Cf) and Berkelium (Bk) metals, e.g., $\operatorname{An}\left[\mathrm{B}_{6} \mathrm{O}_{8}(\mathrm{OH})_{5}\right.$ 
$\left(\mathrm{An}=\mathrm{Cf}\right.$ III and $\left.\mathrm{Bk}^{\mathrm{III}}\right)[171,172]$, have been studied using both GGA and hybrid functionals in conjunction with $\mathrm{NBO}$ analysis [8].

The electronic structures and magnetic properties of $\mathrm{Ar}_{3} \mathrm{U}^{\mathrm{IV}}-\mathrm{L}$ complexes, with $\mathrm{Ar}=\mathrm{C}_{5}\left(\mathrm{CH}_{3}\right)_{4} \mathrm{H}^{-}$ or $\mathrm{C}_{5} \mathrm{H}_{5}{ }^{-}$and $\mathrm{L}=\mathrm{CH}_{3}, \mathrm{NO}$, and $\mathrm{Cl}$ have been investigated recently (2014) [67]. The study aimed to provide $a b$ initio data for the magnetic susceptibilities, assignments of the low-energy parts of the electronic spectra, as well as characterizations of selected states based on natural orbitals and their occupations. For the ground states, relativistic CASSCF and CASPT2 calculations were compared to scalar relativistic DFT using the ZORA Hamiltonian. As concluded by the authors, for the nitrosyl complex, the ground state is a closed-shell spin-singlet i.e., a nonmagnetic ground state. For the other $\mathrm{L}=\mathrm{Cl}$ and $\mathrm{CH}_{3}$ complexes, the ground states are triplets, with no orbital degeneracy for the chloride complexes and an orbital-doublet for the methyl complex. Furthermore, the nature of the electronic ground state and low-energy excited states is evidenced by the susceptibility curves displaying linear $\chi \mathrm{T}$ [67]. The computed susceptibilities from ab initio calculations agree well with available experimental data; e.g., for the $\left(\mathrm{C}_{5} \mathrm{Me}_{4} \mathrm{H}\right)_{3} \mathrm{UCl}$ complex, the $a b$ initio calculated temperature-independent paramagnetism (TIP) susceptibility $\chi_{\mathrm{TIP}}$ is 8.52 and 10.44 (units of $10^{3} \mathrm{~cm}^{3} \mathrm{~mol}^{-1}$ ) for the experimental and optimized structure, respectively.

DFT-based calculations have also been reported [168] and proved to correctly reproduce chemical shifts of diamagnetic uranium(VI) compounds. DFT benchmarking calculations of ${ }^{1} \mathrm{H}$ and ${ }^{13} \mathrm{C}$ NMR chemical shifts of closed shell U(VI) systems for which experimental data are available (Figure 34), were reported [79]. Different levels of GGA and hybrid functionals were employed, i.e., B3LYP [86,87], PBE [148], PBE0 [149], LC- $\omega$ PBE [173,174], TPSS and TPSSh [175,176] and also including the Grimme's D3 dispersion corrections [150,157]. Overall, it was found that the most robust methodology for obtaining accurate geometries is the PBE functional with Grimme's D3 dispersion corrections, whereas for ${ }^{1} \mathrm{H}$ and ${ }^{13} \mathrm{C}$ NMR chemical shifts, no special recommendation emerges regarding the best choice of density functional, although for spin-spin couplings, the LC- $\omega$ PBE functional with solvent corrections is a good approach.

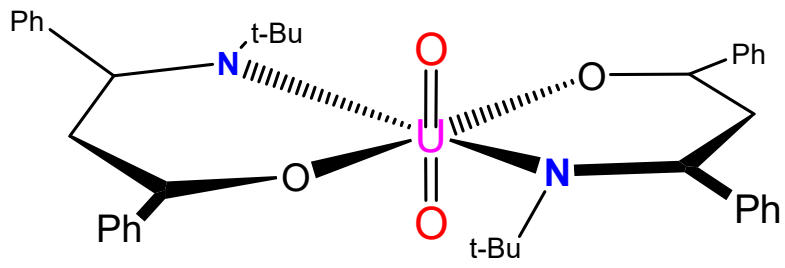

(a)

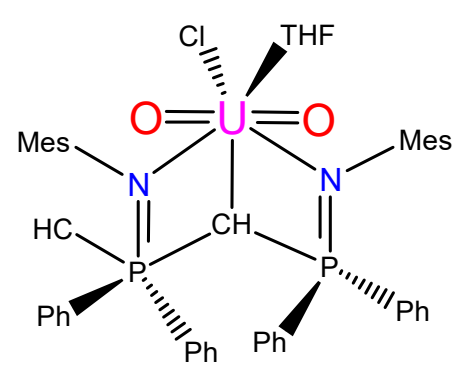

(b)

Figure 34. Structures of Uranyl(VI) monomers (a) $\beta$-Ketoiminate and (b) Carbenes Complexes [79].

The authors concluded that among the investigated approaches, the disagreement with experiment of the averaged ${ }^{1} \mathrm{H}$ and ${ }^{13} \mathrm{C}$ chemical shifts rarely exceeds $15 \%$ deviation for the studied $\mathrm{U}(\mathrm{VI})$ compounds. The geometry employed has relatively little effect on the ${ }^{1} \mathrm{H}$ and ${ }^{13} \mathrm{C}$ chemical shifts, and increasing the quality of the basis set to include triple and quadruple polarizations does not bring any improvement. For spin-spin couplings, the inclusion of relativistic effects with ZORA including spin-orbit coupling (SOC) led to a less dispersed set of results for ${ }^{13} \mathrm{C} N M R$ signals relatively to scalar ZORA calculations.

Autschbach and Coll. $[169,170]$ have recently (2016) investigated theoretically using DFT calculations combined with two-component ZORA and four-component Dirac-Kohn-Sham (DKS) relativistic frameworks, the SOC effects in a uranium(VI) complex regarding NMR chemical shifts. Gas-phase structures were optimized using def2-TZVP basis sets and the PBE functional [148], as well as with two hybrid PBE0 [149] and B3LYP functionals [86,87]. Bulk solvent effects on the optimized structures and on the computed NMR shieldings were simulated via the conductor-like screening 
model (COSMO) [169]. Their study aimed to reassess the giant spin-orbit effects on NMR shifts observed for closed shell uranium(VI) complexes, investigating the role of the exchange-correlation response kernel. As reported by the authors [169], the considered exchange-correlation kernel in two-component ZORA/DFT calculations is crucial to properly predict the giant ${ }^{1} \mathrm{H}$ NMR shifts in closed-shell uranium(VI) hydride complexes, and also of the extremely large SOC induced ${ }^{13} \mathrm{C}$ shifts for uranium(VI)-bound carbon atoms. The range for unknown shifts with the revised approach was successfully predicted, and further predictions have been made for complexes that are synthetically known.

Finally, the magnetic susceptibility of actinide(III) cations has been intensively investigated by synergetic experimental and theoretical study, as reported by H. Bolvin and Coll. [177]. Through DFT and SO-CASPT2 calculations, the authors aimed to rationalize the experimental magnetic susceptibilities of $\left[\mathrm{An}\left(\mathrm{H}_{2} \mathrm{O}\right)_{9}\right]\left(\mathrm{CF}_{3} \mathrm{SO}_{3}\right)$ actinide(III) aqua complexes ( $\mathrm{An}=\mathrm{Pu}, \mathrm{Am}$ and $\mathrm{Cm}$ ). The geometry optimizations were performed using the B3LYP functional and an implicit solvation model. Once magnetic susceptibility measurements of An(III) cations were corrected from radioactivity effects, SOC-CASPT2 calculations have been used on free ions and aquo complexes to calculate the electronic structure explaining the magnetic properties of $\mathrm{Pu}(\mathrm{III}), \mathrm{Am}(\mathrm{III})$ and $\mathrm{Cm}(\mathrm{III})$. EPR is a useful tool to probe molecular magnetic properties. This tool was used to study $\mathrm{U}(\mathrm{V})$ nitride complexes [178]. The relative importance of the investigated spin-orbit and crystal field interactions explains the different ground states of the nitride complexes relative to oxo isoelectronic species. In addition, $\mathrm{U}(\mathrm{V})-\mathrm{U}(\mathrm{V})$ super-exchange coupling in dimers of these complexes has been studied in relation with EPR experiments [178]. Through EPR and magnetic susceptibility measurements, another $\mathrm{U}(\mathrm{V})-\mathrm{U}(\mathrm{V})$ system, namely $\left.\left.\mathrm{U}^{\mathrm{Ar}} \mathrm{OSeO}^{\mathrm{Ar}}\right]_{2}(\mathrm{THF})\right\}_{2}\left(\mu_{2}-\mathrm{OC}_{6} \mathrm{H}_{4} \mathrm{O}\right)$, which is found to exhibit unusual magnetic properties, also deserves to be highlighted [179].

\section{Conclusions}

The DFT computation of magnetic coupling constants of polynuclear actinide complexes, mainly of uranium, is now well documented. Several magnetic dinuclear or trinuclear uranium complexes have been successfully investigated; the tried and tested methodology makes use of the broken symmetry approach and a hybrid DFT functional, mainly the B3LYP one. A variety of bridging ligands between the uranium centers have been considered either experimentally or theoretically; among them, imido or ketimide phenyl and benzoquinonoide-based conjugated bridges, but also oxo, nitrido and chalcogeno bridges. Bis- and tris-uranyl-based complexes have also been investigated, as well as inverted-sandwich uranium species. Complexes containing uranium in different oxidation states, $\mathrm{U}(\mathrm{V}), \mathrm{U}(\mathrm{IV})$ and $\mathrm{U}(\mathrm{III})$ leading to magnetic electron configurations, $5 \mathrm{f}^{1}-5 \mathrm{f}^{1}, 5 \mathrm{f}^{2}-5 \mathrm{f}^{2}$ and $5 \mathrm{f}^{3}-5 \mathrm{f}^{3}$ have been studied; the ferromagnetic or antiferromagnetic character of the coupling is generally correctly predicted by DFT computations. The magnetic properties of such complexes arise from spin polarization and super-exchange, which are rationalized thanks to frontier $\mathrm{MO}$ and spin density analyses. DFT studies regarding mononuclear uranium complexes, SMMs and mixed $5 \mathrm{f}-3 \mathrm{~d}$ or $5 \mathrm{f}-4 \mathrm{f}$ actinide-transition metal and actinide-lanthanide species, are very scarce in the literature.

Encouraging results have been obtained over recent decades by applying DFT calculations to investigate and rationalize magnetic exchange coupling within actinide polynuclear systems. The generally good agreement between DFT results and the experimental findings gives us confidence that this computationally-cheap approach will remain useful, even if more sophisticated and accurate post-Hartree-Fock treatments will be more developed in the future, thanks to the increasing power of computers.

Author Contributions: Conceptualization, A.B. and L.B.; Methodology, A.B. and L.B.; Writing-Original Draft Preparation, L.B.; Writing-Review \& Editing, L.B., B.L.G. and A.B.; Project Administration, A.B.; Funding Acquisition, L.B., B.L.G. and A.B. 
Funding: Programme Recherche-Formation Universitaire (PRFU) Grant number: B00L01UN250120180015 from Direction Générale Recherche Scientifique et Développement Technologique (DGRSDT) and Université des frères Mentouri of Constantine 1 (Algeria).

Acknowledgments: We acknowledge the High Performance Computing (HPC) resources of Centre Informatique National de l'Enseignement Supérieur (CINES) and of Institut du Développement et des Ressources en Informatique Scientifique (IDRIS) under the allocations 2017 and 2018-[x2016080649] made by the Grand Equipement National de Calcul Intensif (GENCI).

Conflicts of Interest: The authors declare no conflict of interest.

\section{References}

1. Rinehart, J.D.; Harris, T.D.; Kozimor, S.A.; Bartlett, B.M.; Long, J.R. Magnetic Exchange Coupling in Actinide-Containing Molecules. Inorg. Chem. 2009, 48, 3382-3395. [CrossRef] [PubMed]

2. Lukens, W.W.; Walter, M.D. Quantifying Exchange Coupling in f-Ion Pairs Using the Diamagnetic Substitution Method. Inorg. Chem. 2010, 49, 4458-4465. [CrossRef] [PubMed]

3. Liddle, S.T.; van Slageren, J. Lanthanides and Actinides. In Molecular Magnetism; Layfield, R.A., Murugesu, M., Eds.; Wiley-VCH: Weinheim, Germany, 2015; pp. 315-340.

4. Feng, M.; Tong, M.-L. Single Ion Magnets from 3d to 5f: Developmentsand Strategies. Chem. Eur. J. 2018, 24, 7574-7594. [CrossRef] [PubMed]

5. Boucekkine, A.; Belkhiri, L. f-Element Complexes. In Comprehensive Inorganic Chemistry II; Reedijk, J., Poeppelmeier, K., Eds.; Elsevier: Oxford, UK, 2013; Volume 9, pp. 277-319.

6. Kindra, D.R.; Evans, W. Magnetic Susceptibility of Uranium Complexes. J. Chem. Rev. 2014, 114, 8865-8882. [CrossRef] [PubMed]

7. Magnani, N. Spectroscopic and magnetic investigations of actinide-based nanomagnets. Int. J. Quantum Chem. 2014, 114, 755-759. [CrossRef]

8. Kaltsoyannis, N. Transuranic Computational Chemistry. Chem. Eur. J. 2018, 24, 2815-2825. [CrossRef] [PubMed]

9. Rosen, R.K.; Andersen, R.A.; Edelstein, N.M.J. [( $\left(\mathrm{MeC}_{5} \mathrm{H}_{4}\right)_{3} \mathrm{U}_{2}\left[\mu .-1,4-\mathrm{N}_{2} \mathrm{C}_{6} \mathrm{H}_{4}\right]$ : A bimetallic molecule with antiferromagnetic coupling between the uranium centers. J. Am. Chem. Soc. 1990, 112, 4588-4590. [CrossRef]

10. Diaconescu, P.L.; Arnold, P.L.; Baker, T.A.; Mindiola, D.J.; Cummins, C.C. Arene-Bridged Diuranium Complexes: Inverted Sandwiches Supported by $\delta$ Backbonding. J. Am. Chem. Soc. 2000, 122, 6108-6109. [CrossRef]

11. Diaconescu, P.L.; Cummins, C.C. Diuranium Inverted Sandwiches: Involving Naphthalene and Cyclooctatetraene. J. Am. Chem. Soc. 2002, 124, 7660-7661. [CrossRef]

12. Odom, A.L.; Arnold, P.L.; Cummins, C.C. Heterodinuclear uranium/molybdenum dinitrogen complexes. J. Am. Chem. Soc. 1998, 120, 5836. [CrossRef]

13. Fox, A.R.; Arnold, P.L.; Cummins, C.C. Uranium Nitrogen Multiple Bonding: Isostructural Anionic, Neutral, and Cationic Uranium Nitride Complexes Featuring a Linear $\mathrm{U}=\mathrm{N}=\mathrm{U}$ Core. J. Am. Chem. Soc. 2010, 132, 3250-3251. [CrossRef] [PubMed]

14. Fox, A.R.; Creutz, S.E.; Cummins, C.C. A bimetallic uranium $\mu$-dicarbide complex: Synthesis, X-ray crystal structure, and bonding. Dalton Trans. 2010, 39, 6632-6634. [CrossRef] [PubMed]

15. Diaconescu, P.L.; Cummins, C.C. $\mu-\eta^{6}, \eta^{6}$-Arene-Bridged Diuranium Hexakisketimide Complexes Isolable in Two States of Charge. Inorg. Chem. 2012, 51, 2902-2916. [CrossRef] [PubMed]

16. Vlaisavljevich, B.; Diaconescu, P.L.; Lukens, W.L.; Gagliardi, L.; Cummins, C.C. Investigations of the Electronic Structure of Arene-Bridged Diuranium Complexes. Organometallics 2013, 32, 1341-1352. [CrossRef]

17. Korobkov, I.; Gambarotta, S.; Yap, G.P.A. Dinuclear Trivalent and Mixed-Valence Uranium [(-CH2-)5]4-calix[4]tetrapyrrole Complexes with Short Intermetallic Distances. Organometallics 2001, 20, 5440-5445. [CrossRef]

18. Monreal, M.J.; Carver, C.T.; Diaconescu, P.L. Redox Processes in a Uranium Bis(1,1'-diamidoferrocene) Complex. Inorg. Chem. 2007, 46, 7226-7228. [CrossRef] [PubMed]

19. Evans, W.J.; Kozimor, S.A.; Ziller, J.W.; Kaltsoyannis, N. Structure, Reactivity, and Density Functional Theory Analysis of the Six-Electron Reductant, $\left[\left(\mathrm{C}_{5} \mathrm{Me}_{5}\right)_{2} \mathrm{U}_{2}\left(\mu-\eta^{6}: \eta^{6}-\mathrm{C}_{6} \mathrm{H}_{6}\right)\right.$, Synthesized via a New Mode of $\left(\mathrm{C}_{5} \mathrm{Me}_{5}\right)_{3} \mathrm{M}$ Reactivity. J. Am. Chem. Soc. 2004, 126, 14533-14547. [CrossRef] 
20. Evans, W.J.; Miller, K.A.; DiPasquale, A.G.; Rheingold, A.L.; Stewart, T.J.; Bau, R. A Crystallizable f-Element Tuck-In Complex: The Tuck-In Tuck-over Uranium Metallocene $\left(\mathrm{C}_{5} \mathrm{Me}_{5}\right) \mathrm{U}$ $\left[\mu-\eta^{5}: \eta^{1}: \eta^{1}-\mathrm{C}_{5} \mathrm{Me}_{3}\left(\mathrm{CH}_{2}\right)_{2}\right](\mu-\mathrm{H})_{2} \mathrm{U}\left(\mathrm{C}_{5} \mathrm{Me}_{5}\right)_{2}$. Angew. Chem. Int. Ed. 2008, 47, 5075-5078. [CrossRef]

21. Rinehart, J.D.; Bartlett, B.M.; Kozimor, S.A.; Long, J.R. Ferromagnetic exchange coupling in the linear, chloride-bridged cluster (cyclam) $\mathrm{Co}^{\mathrm{II}}\left[(\mu-\mathrm{Cl}) \mathrm{U}^{\mathrm{IV}}\left(\mathrm{Me}_{2} \mathrm{Pz}\right)_{4}\right]_{2}$. Inorg. Chim. Acta 2008, 361, 3534-3538. [CrossRef]

22. Spencer, L.P.; Yang, P.; Scott, B.L.; Batista, E.R.; Boncella, J.M. Oxidative Addition to U(V)-U(V) Dimers: Facile Routes to Uranium(VI) Bis(imido) Complexes. Inorg. Chem. 2009, 48, 11615-11623. [CrossRef]

23. Nocton, G.; Horeglad, P.; Pécaut, J.; Mazzanti, M. Polynuclear cation-cation complexes of pentavalent uranyl: Relating stability and magnetic properties to structure. J. Am. Chem. Soc. 2008, 130, 16633-16645. [CrossRef] [PubMed]

24. Mougel, V.; Horeglad, P.; Nocton, G.; Pécaut, J.; Mazzanti, M. Stable Pentavalent Uranyl Species and Selective Assembly of a Polymetallic Mixed-Valent Uranyl Complex by Cation-Cation Interactions. Angew. Chem. Int. Ed. 2009, 121, 8629-8632. [CrossRef]

25. Nocton, G.; Horeglad, P.; Vetere, V.; Pécaut, J.; Dubois, L.; Maldivi, P.; Edelstein, N.M.; Mazzanti, M. Synthesis, Structure, and Bonding of Stable Complexes of Pentavalent Urany. J. Am. Chem. Soc. 2010, 132, 495-508. [CrossRef] [PubMed]

26. Mougel, V.; Horeglad, P.; Nocton, G.; Pecaut, J.; Mazzanti, M. Cation-cation complexes of pentavalent uranyl: From disproportionation intermediates to stable clusters. Chem. Eur. J. 2010, 16, 14365-14377. [CrossRef] [PubMed]

27. Chatelain, L.; Mougel, V.; Pécautand, J.; Mazzanti, M. Magnetic communication cation-cation trimer of pentavalent uranyl. Chem. Sci. 2012, 3, 1075-1079. [CrossRef]

28. Mougel, V.; Pecaut, J.; Mazzanti, M. New polynuclear U(IV)-U(V) complexes from U(IV) mediated uranyl(V) Disproportionation. Chem. Commun. 2012, 48, 868-870. [CrossRef] [PubMed]

29. Mougel, V.; Chatelain, L.; Hermle, J.; Caciuffo, R.; Colineau, E.; Tuna, F.; Magnani, N.; De Geyer, A.; Pécaut, J.; Mazzanti, M. A uranium-based UO2(+)-Mn2+ single-chain magnet assembled trough cation-cation interactions. Angew. Chem. Int. Ed. 2014, 53, 819-823. [CrossRef]

30. Chatelain, L.; Pécaut, J.; Tuna, F.; Mazzanti, M. Heterometallic Fe2II-UV and Ni2II-UV Exchange-Coupled Single-Molecule Magnets: Effect of the 3 d Ion on the Magnetic Properties. Chem. Eur. J. 2015, 21, 18038-18042. [CrossRef]

31. Chatelain, L.; Tuna, F.; Pécaut, J.; Mazzanti, M. A zig-zag uranyl(v)-Mn(ii) single chain magnet with a high relaxation barrier. Chem. Commun. 2015, 51, 11309-11312. [CrossRef]

32. Chatelain, L.; Tuna, F.; Pécaut, J.; Mazzanti, M. Synthesis and SMM behaviour of trinuclear versus dinuclear 3d-5f uranyl(v)-cobalt(ii) cation-cation complexes. Dalton Trans. 2017, 46, 5498-5502. [CrossRef]

33. Magnani, N.; Colineau, E.; Eloirdi, R.; Griveau, J.-C.; Caciuffo, R.; Cornet, S.M.; May, I.; Sharrad, C.A.; Collison, D.; Winpenny, R.E.P. Superexchange Coupling and Slow Magnetic Relaxation in a Transuranium Polymetallic Complex. Phys. Rev. Lett. 2010, 104, 197202. [CrossRef] [PubMed]

34. Tsoureas, N.; Kilpatrick, A.F.R.; Inmana, C.J.; Cloke, F.G.N. Steric control of redox events in organo-uranium chemistry: Synthesis and characterisation of $\mathrm{U}(\mathrm{V})$ oxo and nitrido complexes. Chem. Sci. 2016, 7, 4624-4632. [CrossRef] [PubMed]

35. Wooles, A.; Mills, D.; Tuna, F.; Mcinnes, E.; Law, G.; Fuller, A.; Kremer, F.; Ridgway, M.; Lewis, W.; Gagliardi, L.; et al. Uranium(III)-Carbon Multiple Bonding Supported by Arene $\delta$-Bonding in Mixed-Valence Hexauranium Nanometre-Scale Rings. Nat. Commun. 2018, 9, 2097. [CrossRef] [PubMed]

36. Wooles, A.J.; Lewis, W.; Blake, A.J.; Liddle, S.T. $\beta$-Diketiminate Derivatives of Alkali Metals and Uranium. Organometallics 2013, 32, 5058-5070. [CrossRef]

37. Gardner, B.M.; King, D.M.; Tuna, F.; Wooles, A.J.; Chilton, N.F.; Liddle, S.T. Assessing Crystal Field and Magnetic Interactions in Diuranium $\mathrm{U}^{\mathrm{IV}}-\mathrm{E}-\mathrm{U}^{\mathrm{IV}}$ cores (E = S, Se, Te). Chem. Sci. 2017, 8, 6207-6217. [CrossRef] [PubMed]

38. Patel, D.; Moro, F.; McMaster, J.; Lewis, W.; Blake, A.J.; Liddle, S.T. A Formal High Oxidation State Inverse-Sandwich Diuranium Complex: A New Route to f-Block-Metal Bonds. Angew. Chem. Int. Ed. 2011, 50, 10388-10392. [CrossRef] [PubMed] 
39. Schelter, E.J.; Yang, P.; Scott, B.L.; Thompson, J.D.; Martin, R.L.; Hay, P.J.; Morris, D.E.; Kiplinger, J.L. Systematic Studies of Early Actinide Complexes: Uranium(IV) Fluoroketimides. Inorg. Chem. 2007, 46, 7477-7488. [CrossRef]

40. Graves, C.R.; Yang, P.; Kozimor, S.A.; Vaughn, A.E.; Clark, D.L.; Conradson, S.D.; Schelter, E.J.; Scott, B.L.; Thompson, J.D.; Hay, P.J.; et al. Organometallic Uranium(V)-Imido Halide Complexes: From Synthesis to Electronic Structure and Bonding. J. Am. Chem. Soc. 2008, 130, 5272-5285. [CrossRef]

41. Schelter, E.J.; Wu, R.; Scott, B.L.; Thompson, J.D.; Morris, D.E.; Kiplinger, J.L. Mixed Valency in a Uranium Multimetallic Complex. Angew. Chem. Int. Ed. 2008, 47, 2993-2996. [CrossRef]

42. Minasian, S.G.; Krinsky, J.L.; Rinehart, J.D.; Copping, R.; Tyliszczak, T.; Janousch, M.; Shuh, D.K.; Arnold, J. A comparison of $4 \mathrm{f}$ vs $5 \mathrm{f}$ metal-metal bonds in $\left(\mathrm{CpSiMe}_{3}\right)_{3} \mathrm{M}-\mathrm{ECP} *\left(\mathrm{M}=\mathrm{Nd}, \mathrm{U}\right.$; $\left.\mathrm{E}=\mathrm{Al}, \mathrm{Ga} ; \mathrm{Cp}^{*}=\mathrm{C}_{5} \mathrm{Me}_{5}\right)$ : Synthesis, thermodynamics, magnetism, and electronic structure. J. Am. Chem. Soc. 2009, 131, 13767-13783. [CrossRef]

43. Salmon, L.; Thuéry, P.; Rivière, E.; Marrot, J.; Girerd, J.-J.; Ephritikhine, M. Syntheses, X-Ray Crystal Structures, and Magnetic Properties of Novel Linear $\mathrm{M}_{2}^{\mathrm{II}} \mathrm{U}^{\mathrm{IV}}$ Complexes $(\mathrm{M}=\mathrm{Co}, \mathrm{Ni}, \mathrm{Cu}, \mathrm{Zn})$. Chem. Eur. J. 2002, 8 , 773-783. [CrossRef]

44. Salmon, L.; Thuéry, P.; Rivière, E.; Girerd, J.-J.; Ephritikhine, M. Versatility of the nature of the magnetic $\mathrm{Cu}(\mathrm{II})-\mathrm{U}(\mathrm{IV})$ interaction. Syntheses, crystal structures and magnetic properties of $\mathrm{Cu} 2 \mathrm{U}$ and $\mathrm{CuU}$ compounds. Dalton Trans. 2003, 2872-2880. [CrossRef]

45. Salmon, L.; Thuéry, P.; Rivière, E.; Girerd, J.-J.; Ephritikhine, M. Synthesis, Structure, and Magnetic Behavior of a Series of Trinuclear Schiff Base Complexes of $5 \mathrm{f}\left(\mathrm{U}^{\mathrm{IV}}, \mathrm{Th}^{\mathrm{IV}}\right)$ and $3 \mathrm{~d}\left(\mathrm{Cu}^{\mathrm{II}}, \mathrm{Zn}^{\mathrm{II}}\right)$ Ions. Inorg. Chem. 2006, 45, 83-93. [CrossRef] [PubMed]

46. Arnold, P.L.; Love, J.B.; Patel, D. Pentavalent uranyl complexes. Coord. Chem. Rev. 2009, 253, $1973-1978$. [CrossRef]

47. Arnold, P.L.; Cowie, B.E.; Suvova, M.; Zegke, M.; Magnani, N.; Colineau, E.; Griveau, J.-C.; Caciuffo, R.; Love, J.B. Axially Symmetric U-O-Ln- and U-O-U-Containing Molecules from the Control of Uranyl Reduction with Simple f-Block Halides. Angew. Chem. Int. Ed. 2017, 129, 10915-10919. [CrossRef]

48. Arnold, P.L.; Jones, G.M.; Pan, Q.-J.; Schreckenbach, G.; Love, J.B. Co-linear, double-uranyl coordination by an expanded Schiff-base polypyrrole macrocycle. Dalton Trans. 2012, 41, 6595-6597. [CrossRef] [PubMed]

49. Arnold, P.L.; Jones, G.M.; Odoh, S.O.; Schreckenbach, G.; Magnani, N.; Love, J.B. Strongly coupled binuclear uranium-oxo complexes from uranyl oxo rearrangement and reductive silylation. Nat. Chem. 2012, 4, 221-227. [CrossRef]

50. Jones, G.M.; Arnold, P.L.; Love, J.B. Oxo-Group-14-Element Bond Formation in Binuclear Uranium(V) Pacman Complexes. Chem. Eur. J. 2013, 19, 10287-10294. [CrossRef]

51. Cowie, B.E.; Nichol, G.S.; Love, J.B.; Arnold, P.L. Double uranium oxo cations derived from uranyl by borane or silane reduction. Chem. Commun. 2018, 54, 3839-3842. [CrossRef]

52. Larch, C.P.; Cloke, F.G.N.; Hitchcock, P.B. Activation and reduction of diethyl ether by low valent uranium: Formation of the trimetallic, mixed valence uranium oxo species $\left[\mathrm{U}\left(\mathrm{Cp}^{\mathrm{RR}}\right)(\mu-\mathrm{I})_{2}\right]_{3}\left(\mu^{3}-\mathrm{O}\right)\left(\mathrm{Cp}^{\mathrm{RR}}=\mathrm{C}_{5} \mathrm{Me}_{5}\right.$, $\mathrm{C}_{5} \mathrm{Me}_{4} \mathrm{H}, \mathrm{C}_{5} \mathrm{H}_{4} \mathrm{SiMe}_{3}$ ). Chem. Commun. 2008, 82-84. [CrossRef]

53. Rinehart, J.D.; Long, J.R. Slow Magnetic Relaxation in a Trigonal Prismatic Uranium(III) Complex. J. Am. Chem. Soc. 2009, 131, 12558-12559. [CrossRef] [PubMed]

54. Ishikawa, N.; Sugita, M.; Ishikawa, T.; Koshihara, S.; Kaizu, Y. Lanthanide Double-Decker Complexes Functioning as Magnets at the Single-Molecular Level. J. Am. Chem. Soc. 2003, 125, 8694. [CrossRef] [PubMed]

55. Ishikawa, N.; Sugita, M.; Ishikawa, T.; Koshihara, S.; Kaizu, Y. Mononuclear Lanthanide Complexes with a Long Magnetization Relaxation Time at High Temperatures: A New Category of Magnets at the Single-Molecular Level. J. Phys. Chem. B 2004, 108, 11265-11271. [CrossRef]

56. Rinehart, J.D.; Meihaus, K.R.; Long, J.R. Observation of a Secondary Slow Relaxation Process for the Field-Induced Single-Molecule Magnet $\mathrm{U}\left(\mathrm{H}_{2} \mathrm{BPz}_{2}\right)_{3}$. J. Am. Chem. Soc. 2010, 132, 7572-7573. [CrossRef] [PubMed]

57. Meihaus, K.R.; Rinehart, J.D.; Long, J.R. Dilution-Induced Slow Magnetic Relaxation and Anomalous Hysteresis in Trigonal Prismatic Dysprosium(III) and Uranium(III) Complexes. Inorg. Chem. 2011, 50, 8484-8489. [CrossRef] [PubMed] 
58. Rinehart, J.D.; Long, J.R. Slow magnetic relaxation in homoleptic trispyrazolylborate complexes of neodymium(III) and uranium(III). Dalton Trans. 2012, 41, 13572. [CrossRef] [PubMed]

59. Antunes, M.A.; Pereira, L.C.; Santos, I.C.; Mazzanti, M.; Marcalo, J.; Almeida, M. U(Tp(Me2))(2)(bipy) (+): A Cationic Uranium(III) Complex with Single-Molecule-Magnet Behavior. Inorg. Chem. 2011, 50, 9915-9917. [CrossRef]

60. Mills, D.P.; Moro, F.; McMa ster, J.; van Slageren, J.; Lewis, W.; Blake, A.J.; Liddle, S.T. A Delocalized Arene-Bridged Diuranium Single-Molecule Magnet. Nat. Chem. 2011, 3, 454-460. [CrossRef]

61. Mougel, V.; Chatelain, L.; Pecaut, J.; Caciuffo, R.; Colineau, E.; Griveau, J.C.; Mazzanti, M. Uranium and Manganese Assembled in a Wheel-Shaped Nanoscale Single-Molecule Magnet with High Spin-Reversal Barrier. Nat. Chem. 2012, 4, 1011-1017. [CrossRef]

62. King, D.M.; Tuna, F.; McMaster, J.; Lewis, W.; Blake, A.J.; McInnes, E.J.; Liddle, S.T. Single-Molecule Magnetism in a Single-Ion Triamidoamine Uranium (V) Terminal Mono-Oxo Complex. Angew. Chem. Int. Ed. 2013, 52, 4921-4924. [CrossRef]

63. Spivak, M.; Vogiatzis, K.D.; Cramer, C.J.; de Graaf, C.; Gagliardi, L. Quantum Chemical Characterization of Single Molecule Magnets Based on Uranium. J. Phys. Chem. A 2017, 121, 1726-1733. [CrossRef] [PubMed]

64. Gaggioli, C.A.; Gagliardi, L. Theoretical Investigation of Plutonium-Based Single-Molecule Magnets. Inorg. Chem. 2018, 57, 8098-8105. [CrossRef]

65. Patel, D.; Tuna, F.; McInnes, E.J.; McMaster, J.; Lewis, W.; Blake, A.J.; Liddle, S.T. A triamido-uranium(V) inverse-sandwich $10 \pi$-toluene tetraanion arene complex. Dalton Trans. 2013, 42, 5224-5227. [CrossRef] [PubMed]

66. Pereira, L.C.; Camp, C.; Coutinho, J.T.; Chatelain, L.; Maldivi, P.; Almeida, M.; Mazzanti, M. Single-MoleculeMagnet Behavior in Mononuclear Homoleptic Tetrahedral Uranium(III) Complexes. Inorg. Chem. 2014, 53, 11809-11811. [CrossRef] [PubMed]

67. Gendron, F.; Le Guennic, B.; Autschbach, J. Magnetic Properties and Electronic Structures of $\mathrm{Ar}_{3} \mathrm{U}^{\mathrm{IV}}-\mathrm{L}$ Complexes with $\mathrm{Ar}=\mathrm{C}_{5}\left(\mathrm{CH}_{3}\right)_{4} \mathrm{H}^{-}$or $\mathrm{C}_{5} \mathrm{H}_{5}{ }^{-}$and $\mathrm{L}=\mathrm{CH}_{3}, \mathrm{NO}$, and C. Inorg. Chem. 2014, 53, 13174-13187. [CrossRef] [PubMed]

68. Le Roy, J.J.; Gorelsky, S.I.; Korobkov, I.; Murugesu, M. Slow Magnetic Relaxation in U(III) and Nd(III) Cyclooctatetraenyl Complexes. Organometallics 2015, 34, 1415-1418. [CrossRef]

69. Chatelain, L.; Walsh, J.P.S.; Pécaut, J.; Tuna, F.; Mazzanti, M. Self-Assembly of a 3d-5f Trinuclear Single-Molecule Magnet from a Pentavalent Uranyl Complex. Angew. Chem. Int. Ed. 2014, 53, 13434-13438. [CrossRef]

70. Rinehart, J.D.; Long, J.R. Exploiting Single-Ion Anisotropy in the Design of f-Element Single-Molecule Magnets. Chem. Sci. 2011, 2, 2078-2085. [CrossRef]

71. Meihaus, K.R.; Long, J.R. Actinide-Based Single-Molecule Magnets. Dalton Trans. 2015, 44, $2517-2528$. [CrossRef]

72. Liddle, S.T.; van Slageren, J. Improving f-element single molecule magnets. Chem. Soc. Rev. 2015, 44, 6655-6668. [CrossRef]

73. Pedersen, K.S.; Dreiser, J.; Weihe, H.; Sibille, R.; Johannesen, H.V.; Sorensen, M.A.; Nielsen, B.E.; Sigrist, M.; Mutka, H.; Rols, S.; et al. Design of Single-Molecule Magnets: Insufficiency of the Anisotropy Barrier as the Sole Criterion. Inorg. Chem. 2015, 54, 7600-7606. [CrossRef] [PubMed]

74. McAdams, S.G.; Ariciu, A.-M.; Kostopoulos, A.K.; Walsh, J.P.S.; Tuna, F. Molecular single-ion magnets based on lanthanides and actinides: Design considerations and new advances in the context of quantum technologies. Coord. Chem. Rev. 2017, 346, 216-239. [CrossRef]

75. Magnani, N.; Caciuffo, R. Future Directions for Transuranic Single Molecule Magnets. Inorganics 2018, 6, 26. [CrossRef]

76. Jung, J.; Atanasov, M.; Neese, F. Ab Initio Ligand-Field Theory Analysis and Covalency Trends in Actinide and Lanthanide Free Ions and Octahedral Complexes. Inorg. Chem. 2017, 56, 8802-8816. [CrossRef] [PubMed]

77. King, D.M.; Tuna, F.; McInnes, E.J.; McMaster, J.; Lewis, W.; Blake, A.J.; Liddle, S.T. Isolation and Characterization of a Uranium(VI)-Nitride Triple Bond. Nat. Chem. 2013, 5, 482-488. [CrossRef] [PubMed]

78. Neidig, M.L.; Clark, D.L.; Martin, R.L. Covalency in f-element complexes. Coord. Chem. Rev. 2013, 257, 394-406. [CrossRef] 
79. Reta, D.; Ortu, F.; Randall, S.; Mills, D.P.; Chilton, N.F.; Winpenny, R.E.P.; Natrajan, L.; Edwards, B.; Kaltsoyannis, N. The performance of density functional theory for the description of ground and excited state properties of inorganic and organometallic uranium compounds. J. Organomet. Chem. 2018, 857, 58-74. [CrossRef]

80. Söderlind, P.; Kotliar, G.; Haule, K.; Oppeneer, P.M.; Guillaumont, D. Computational Modeling of Actinide Materials and Complexes. MRS Bull. 2010, 35, 883-888. [CrossRef]

81. Gryaznov, D.; Heifets, E.; Sedmidubsky, D. Density functional theory calculations on magnetic properties of actinide compounds. Phys. Chem. Chem. Phys. 2010, 12, 12273-12278. [CrossRef]

82. Bencini, A. Some considerations on the proper use of computational tools in transition metal chemistry. Inorg. Chim. Acta 2008, 361, 3820-3831. [CrossRef]

83. Neese, F. Prediction of molecular properties and molecular spectroscopy with density functional theory: From fundamental theory to exchange-coupling. Coord. Chem. Rev. 2009, 253, 526-563. [CrossRef]

84. Wan, D.; van Gunsteren, W.F.; Chai, Z. Recent advances in computational actinoid chemistry. Chem. Soc. Rev. 2012, 41, 5836-5865. [CrossRef]

85. Schreckenbach, G.; Shamov, G.A. Theoretical actinide molecular science. Acc. Chem. Res. 2010, 43, 19-29. [CrossRef] [PubMed]

86. Becke, A.D. Density-functional thermochemistry. III. The role of exact exchange. J. Chem. Phys. 1993, 98, 5648. [CrossRef]

87. Lee, C.; Yang, W.; Parr, R.G. Development of the Colle-Salvetti correlation-energy formula into a functional of the electron density. Phys. Rev. B Condens. Matter Mater. Phys. 1988, 37, 785. [CrossRef]

88. Noodleman, L.J.; Davidson, E.R. Ligand spin polarization and antiferromagnetic coupling in transition metal dimers. Chem. Phys. 1986, 109, 131-143. [CrossRef]

89. Noodleman, L.J.; Peng, C.Y.; Case, D.A.; Mouesca, J.M. Orbital interactions, electron delocalization and spin coupling in iron-sulfur clusters. Coord. Chem. Rev. 1995, 144, 199-244. [CrossRef]

90. Døssing, A. Recent advances in the coordination chemistry of hydroxo-bridged complexes. Coord. Chem. Rev. 2014, 280, 38-53. [CrossRef]

91. Selmi, W.; Abdelhak, J.; Marchivie, M.; Chastanet, G.; Zid, M.F. An investigation by DFT of the electronic structure and magnetic properties of a novel l-oxo-iron(III) complex with the 1,10-phenathroline ligand. Polyhedron 2017, 123, 441-452. [CrossRef]

92. Ouilia, S.; Beghidja, C.; Beghidja, A.; Belkhiri, L.; Rabu, P. Synthesis, crystal structure, magnetic properties and DFT calculations of new dihydroxo-bridged binuclear chromium(III) based on monodentate mixed ligand. Inorg. Chim. Acta 2018, 476, 54-60. [CrossRef]

93. Ruiz, E.; Cano, J.; Alvarez, S.; Alemany, P. Broken Symmetry Approach to Calculation of Exchange Coupling Constants for Homobinuclear and Heterobinuclear Transition Metal Complexes. J. Comput. Chem. 1999, 20, 1391-1400. [CrossRef]

94. Ruiz, E.; Rodríguez-Fortea, A.; Cano, J.; Alvarez, S.; Alemany, P. About the calculation of exchange coupling constants in polynuclear transition metal complexes. J. Comput. Chem. 2003, 24, 982-989. [CrossRef] [PubMed]

95. Ciofini, I.; Daul, C.A. DFT calculations of molecular magnetic properties of coordination compounds. Coord. Chem. Rev. 2003, 187, 238-239. [CrossRef]

96. Kortus, J. Molecular magnets explored by density functional theory calculations. C. R. Chimie 2007, 10 , 65-67. [CrossRef]

97. Fouqueau, A.; Casida, M.E.; Daku, L.M.L.; Hauser, A.; Neese, F. Comparison of density functionals for energy and structural differences between the high- $\left[{ }^{5} \mathrm{~T}_{2 \mathrm{~g}}:\left(\mathrm{t}_{2 \mathrm{~g}}\right)^{4}\left(\mathrm{eg}^{2}\right)^{2}\right]$ and low- $\left[{ }^{1} \mathrm{~A}_{1 \mathrm{~g}}:\left(\mathrm{t}_{2 \mathrm{~g}}\right)^{6}\left(\mathrm{e}_{\mathrm{g}}\right)^{0}\right]$ spin states of iron(II) coordination compounds. II. More functionals and the hexaminoferrous cation, $[\mathrm{Fe}(\mathrm{NH} 3) 6]^{2+}$. J. Chem. Phys. 2005, 122, 044110. [CrossRef] [PubMed]

98. Adamo, C.; Barone, V.; Bencini, A.; Totti, F.; Ciofini, I. On the Calculation and Modeling of Magnetic Exchange Interactions in Weakly Bonded Systems: The Case of the Ferromagnetic Copper(II) í2-Azido Bridged Complexes. Inorg. Chem. 1999, 38, 1996-2004. [CrossRef] [PubMed]

99. Korzeniak, T.; Desplanches, C.; Podgajny, R.; Giménez-Saiz, C.; Stadnicka, K.; Rams, M.; Sieklucka, B. Magnetostructural Correlations in $\mathrm{Cu}^{\mathrm{II}}-\mathrm{NC}-\mathrm{WV}$ Linkage: The Case of $[\mathrm{CuII}(\text { diimine })]^{2+}-[\mathrm{WV}(\mathrm{CN}) 8]^{3-}$ 0D Assemblies. Inorg. Chem. 2009, 48, 2865-2872. [CrossRef] 
100. Moreira, I.D.; Costa, R.; Filatov, M.; Illas, F. Restricted Ensemble-Referenced Kohn-Sham versus Broken Symmetry Approaches in Density Functional Theory: Magnetic Coupling in $\mathrm{Cu}$ Binuclear Complexes. J. Chem. Theory Comput. 2007, 3, 764-774. [CrossRef]

101. Cramer, C.J.; Truhlar, D.G. Density functional theory for transition metals and transition metal chemistry. Phys. Chem. Chem. Phys. 2009, 11, 10757-10816. [CrossRef]

102. Onofrio, N.; Mouesca, J.M. Analysis of the Singlet Triplet Splitting Computed by the Density Functional TheoryBroken-Symmetry Method: Is It an Exchange Coupling Constant? Inorg. Chem. 2011, 50, 5577-5586. [CrossRef]

103. Zhekova, H.; Seth, M.; Ziegler, T. Introduction of a New Theory for the Calculation of Magnetic Coupling Based on Spin-Flip Constricted Variational Density Functional Theory. Application to Trinuclear Copper Complexes which Model the Native Intermediate in Multicopper Oxidases. J. Chem. Theory Comput. 2011, 7, 1858-1866. [CrossRef] [PubMed]

104. Peralta, J.E.; Melo, J.I. Magnetic Exchange Couplings with Range-Separated Hybrid Density Functionals. J. Chem. Theory Comput. 2010, 6, 1894-1899. [CrossRef] [PubMed]

105. Páez-Hernández, D.; Murillo-López, J.A.; Arratia-Pérez, R. Optical and Magnetic Properties of the Complex Bis(dicyclooctatetraenyl)diuranium. A Theoretical View. Organometallics 2012, 31, 6297-6304. [CrossRef]

106. Spencer, L.P.; Schelter, E.J.; Yang, P.; Gdula, R.L.; Scott, B.L.; Thompson, J.D.; Kiplinger, J.L.; Batista, E.R.; Boncella, J.M. Cation-cation interactions, magnetic communication, and reactivity of the pentavalent uranium ion $\left[\mathrm{U}(\mathrm{NtBu})_{2}\right]^{+}$. Angew. Chem. Int. Ed. 2009, 48, 3795-3798. [CrossRef] [PubMed]

107. Newell, B.S.; Rapp, A.K.; Shores, M.P. Experimental Evidence for Magnetic Exchange in Di- and Trinuclear Uranium(IV) Ethynylbenzene Complexes. Inorg. Chem. 2010, 49, 1595-1606. [CrossRef] [PubMed]

108. Schultz, N.E.; Zhao, Y.; Truhlar, D.G. Density Functionals for Inorganometallic and Organometallic Chemistry. J. Phys. Chem. A 2005, 109, 11127-11143. [CrossRef] [PubMed]

109. Harvey, J.N. On the Accuracy of Density Functional Theory in Transition Metal Chemistry. Annu. Rep. Prog. Chem. Sect. C Phys. Chem. 2006, 102, 203-226. [CrossRef]

110. Cohen, J.; Mori-Sanchez, A.P.; Yang, W.T. Insights into Current Limitations of Density Functional Theory. Science 2008, 321, 792-794. [CrossRef]

111. Monreal, M.J.; Diaconescu, P.L. A Weak Interaction between Iron and Uranium in Uranium Alkyl Complexes Supported by Ferrocene Diamide Ligands. Organometallics 2008, 27, 1702-1706. [CrossRef]

112. Schelter, E.J.; Veauthier, J.M.; Thompson, J.D.; Scott, B.L.; John, K.D.; Morris, D.E.; Kiplinger, J.L. 4f-5f heterotrimetallic complexes exhibiting electrochemical and magnetic communication. J. Am. Chem. Soc. 2006, 128, 2198-2199. [CrossRef]

113. Natrajan, L.; Burdet, F.; Pécaut, J. Mazzanti, M. Synthesis and structure of a stable pentavalent-uranyl coordination polymer. J. Am. Chem. Soc. 2006, 128, 7152-7153. [CrossRef] [PubMed]

114. Lam, O.P.; Heinemann, F.W.; Meyer, K. Activation of elemental S, Se and Te with uranium(III): Bridging $\mathrm{U}-\mathrm{E}-\mathrm{U}(\mathrm{E}=\mathrm{S}, \mathrm{Se})$ and diamond-core complexes $\mathrm{U}-(\mathrm{E}) 2-\mathrm{U}(\mathrm{E}=\mathrm{O}, \mathrm{S}, \mathrm{Se}, \mathrm{Te})$. Chem. Sci. 2011, 2, 1538-1547. [CrossRef]

115. Schmidt, A.-C.; Heinemann, F.W.; Lukens, W.W., Jr.; Meyer, K. Molecular and Electronic Structure of Dinuclear Uranium Bis- $\mu$-Oxo Complexes with Diamond Core Structural Motifs. J. Am. Chem. Soc. 2014, 136, 11980-11993. [CrossRef] [PubMed]

116. Gardner, B.M.; Stewart, J.C.; Davis, A.L.; McMaster, J.; Lewis, W.; Blake, A.J.; Liddle, S.T. Homologation and functionalization of carbon monoxide by a recyclable uranium complex. Proc. Natl. Acad. Sci. USA 2012, 109, 9265-9270. [CrossRef] [PubMed]

117. Le Borgne, T.; Rivière, E.; Marrot, J.; Girerd, J.-J.; Ephritikhine, M. Synthesis, Crystal Structure, and Magnetic Behavior of Linear MUIV Complexes (M = Co, Ni, Cu, Zn). Angew. Chem., Int. Ed. 2000, 39, 1647. [CrossRef]

118. Ephritikhine, M. The vitality of uranium molecular chemistry at the dawn of the XXIst century. Dalton Trans. 2006, 2501. [CrossRef] [PubMed]

119. Arliguie, T.; Lance, M.; Nierlich, M.; Vigner, J.; Ephritikhine, M. Inverse cycloheptatrienyl sandwich complexes. Crystal structure of $\left[\mathrm{U}\left(\mathrm{BH}_{4}\right)_{2}\left(\mathrm{OC}_{4} \mathrm{H}_{8}\right)_{5}\right]\left[\left(\mathrm{BH}_{4}\right)_{3} \mathrm{U}\left(\mu-\eta^{7}, \eta^{7}-\mathrm{C}_{7} \mathrm{H}_{7}\right) \mathrm{U}\left(\mathrm{BH}_{4}\right)_{3}\right]$. J. Chem. Soc. Chem. Commun. 1994, 847-848. [CrossRef]

120. Arliguie, T.; Lance, M.; Nierlich, M.; Vigner, J.; Ephritikhine, M. Synthesis and crystal structure of $\left[\mathrm{K}\left(\mathrm{C}_{2} \mathrm{H}_{24} \mathrm{O}_{6}\right)\right]\left[\mathrm{U}\left(\eta-\mathrm{C}_{7} \mathrm{H}_{7}\right)_{2}\right]$, the first cycloheptatrienyl sandwich compound. J. Chem. Soc. Chem. Commun. 1995, 183-184. [CrossRef] 
121. Camp, C.; Toniolo, D.; Andrez, J.; Pécaut, J.; Mazzanti, M. A versatile route to homo- and hetero-bimetallic $5 \mathrm{f}-5 \mathrm{f}$ and $3 \mathrm{~d}-5 \mathrm{f}$ complexes supported by a redox active ligand framework. Dalton Trans. 2017, 46, 11145-11148. [CrossRef] [PubMed]

122. Kozimor, S.A.; Bartlett, B.M.; Rinehart, J.D.; Long, J.R. Magnetic Exchange Coupling in Chloride-Bridged 5f-3d Heterometallic Complexes Generated via Insertion into a Uranium(IV) Dimethylpyrazolate Dimer. J. Am. Chem. Soc. 2007, 129, 10672-10674. [CrossRef]

123. Arnold, P.L.; Hollis, E.; Nichol, G.S.; Love, J.B.; Griveau, J.C.; Caciuffo, R.; Magnani, N.; Maron, L.; Castro, L.; Yahia, A.; et al. Oxo-functionalization and reduction of the uranyl ion through lanthanide-element bond homolysis: Synthetic, structural, and bonding analysis of a series of singly reduced uranyl-rare earth $5 \mathrm{f}^{1}-4 \mathrm{f}^{\mathrm{n}}$ complexes. J. Am. Chem. Soc. 2013, 135, 3841-3854. [CrossRef] [PubMed]

124. Arnold, P.L.; Patel, D.; Wilson, C.; Love, J.B. Reduction and selective oxo group silylation of the uranyl dication. Nature 2008, 451, 315-317. [CrossRef] [PubMed]

125. Arnold, P.L.; Pecharman, A.F.; Hollis, E.; Yahia, A.; Maron, L.; Parsons, S.; Love, J.B. Uranyl oxo activation and functionalization by metal cation coordination. Nat. Chem. 2010, 2, 1056-1061. [CrossRef] [PubMed]

126. Arnold, P.L.; Hollis, E.; White, F.J.; Magnani, N.; Caciuffo, R.; Love, J.B. Single Electron Uranyl Reduction by a Rare Earth Cation. Angew. Chem. Int. Ed. 2011, 123, 917-920. [CrossRef]

127. Liddle, S.T. The Renaissance of Non-Aqueous Uranium Chemistry. Angew. Chem. Int. Ed. 2015, 54, 8604-8641. [CrossRef] [PubMed]

128. Schelter, E.J.; Veauthier, J.M.; Graves, C.R.; John, K.D.; Scott, B.L.; Thompson, J.D.; Pool-Davis-Tournear, J.A.; Morris, D.E.; Kiplinger, J.L. 1,4-dicyanobenzene as a scaffold for the preparation of bimetallic actinide complexes exhibiting metal-metal communication. Chem. Eur. J. 2008, 14, 7782-7790. [CrossRef] [PubMed]

129. Goodwin, C.A.P.; Tuna, F.; McInnes, E.J.L.; Liddle, S.T.; McMaster, J.; Vitorica-Yrezabal, I.J.; Mills, D.P. $\left[\mathrm{U}^{\mathrm{III}}\left\{\mathrm{N}\left(\mathrm{SiMe}_{2} \mathrm{tBu}\right)_{2}\right\}_{3}\right]$ : A Structurally Authenticated Trigonal Planar Actinide Complex. Chem. Eur. J. 2014, 20, 14579-14583. [CrossRef]

130. Meihaus, K.R.; Minasian, S.G.; Lukens, W.W., Jr.; Kozimor, S.A.; Shuh, D.K.; Tyliszczak, T.; Long, J.R. Influence of Pyrazolate vs. N-Heterocyclic Carbene Ligands on the Slow Magnetic Relaxation of Homoleptic Trischelate Lanthanide(III) and Uranium(III) Complexes. J. Am. Chem. Soc. 2014, 136, 6056-6068. [CrossRef]

131. Coutinho, J.T.; Antunes, M.A.; Pereira, L.C.J.; Bolvin, H.; Marcalo, J.; Mazzanti, M.; Almeida, M. Single-ion magnet behaviour in [U(TpMe2)2I]. Dalton Trans. 2012, 41, 13568-13571. [CrossRef]

132. Cirera, J.; Jiang, Y.; Qin, L.; Zheng, Y.-Z.; Li, G.; Wu, G.; Ruiz, E. Ferromagnetism in polynuclear systems based on non-linear [ $\mathrm{Mn}_{2}{ }_{2} \mathrm{Mn}^{\mathrm{III}}$ ] building blocks. Inorg. Chem. Front. 2016, 3, 1272-1279. [CrossRef]

133. Ishikawa, N.; Iino, T.; Kaizu, Y. Interaction between f-Electronic Systems in Dinuclear Lanthanide Complexes with Phthalocyanines. J. Am. Chem. Soc. 2002, 124, 11440-11447. [CrossRef] [PubMed]

134. Kahn, M.L.; Ballou, R.; Porcher, P.; Kahn, O.; Sutter, J.P. Analytical Determination of the \{Ln-Aminoxyl Radical\} Exchange Interaction Taking into Account Both the Ligand-Field Effect and the Spin-Orbit Coupling of the Lanthanide Ion (Ln=DyIII and HoIII). Chem. Eur. J. 2002, 8, 525-531. [CrossRef]

135. Przychodzen, P.; Pelka, R.; Lewinski, K.; Supel, J.; Rams, M.; Tomala, K.; Sieklucka, B. Tuning of Magnetic Properties of Polynuclear Lanthanide(III)-Octacyanotungstate(V) Systems: Determination of Ligand-Field Parameters and Exchange Interaction. Inorg. Chem. 2007, 46, 8924-8938. [CrossRef] [PubMed]

136. Yamaguchi, T.; Sunatsuki, Y.; Ishida, H.; Kojima, M.; Akashi, H.; Re, N.; Matsumoto, N.; Pochaba, A.; Mrozinski, J. Synthesis, Structures, and Magnetic Properties of Face-Sharing Heterodinuclear Ni(II)-Ln(III) ( $\mathrm{Ln}=\mathrm{Eu}, \mathrm{Gd}, \mathrm{Tb}$, Dy) Complexes. Inorg. Chem. 2008, 47, 5736-5745. [CrossRef] [PubMed]

137. Sorace, L.; Sangregorio, C.; Figuerola, A.; Benelli, C.; Gatteschi, D. Magnetic Interactions and Magnetic Anisotropy in Exchange Coupled $4 \mathrm{f}-3 \mathrm{~d}$ Systems: A Case Study of a Heterodinuclear $\mathrm{Ce}^{3+}-\mathrm{Fe}^{3+}$ Cyanide-Bridged Complex. Chem. Eur. J. 2009, 15, 1377-1388. [CrossRef] [PubMed]

138. Tangoulis, V.; Estrader, M.; Figuerola, A.; Ribas, J.; Diaz, C. Anisotropic exchange interactions in hetero-one-dimensional $\mathrm{Ln}^{3+}-\mathrm{M}^{3+}$ systems $\left(\mathrm{Ln}^{3+}=\mathrm{Er}, \mathrm{Yb} ; \mathrm{M}^{3+}=\mathrm{Cr}\right.$, FeLS): Magnetometry and Dual Mode X-band Electron Paramagnetic Resonance spectroscopic studies. Chem. Phys. 2007, 336, 74-82. [CrossRef]

139. Santini, P.; Carretta, S.; Amoretti, G.; Caciuffo, R.; Magnani, N.; Lander, G.H. Multipolar interactions in f-electron systems: The paradigm of actinide dioxides. Rev. Mod. Phys. 2009, 81, 807-863. [CrossRef]

140. Yamaguchi, K.; Jensen, F.; Dorigo, A.; Houk, K.N. A spin correction procedure for unrestricted Hartree-Fock and Møller-Plesset wavefunctions for singlet diradicals and polyradicals. Chem. Phys. Lett. 1988, 149, 537. [CrossRef] 
141. Yamaguchi, K.; Namimoto, H.; Fueno, T.; Nogami, T.; Shirota, Y. Possibilities of organic ferromagnets and ferrimagnets by the use of charge-transfer (CT) complexes with radical substituents. Ab initio MO studies. Chem. Phys. Lett. 1990, 166, 408. [CrossRef]

142. Soda, T.; Kitagawa, Y.; Onishi, T.; Takano, Y.; Shigeta, Y.; Nagao, H.; Yoshioka, Y.; Yamaguchi, K. Ab initio computations of effective exchange integrals for $\mathrm{H}-\mathrm{H}, \mathrm{H}-\mathrm{He}-\mathrm{H}$ and $\mathrm{Mn}_{2} \mathrm{O}_{2}$ complex: Comparison of broken-symmetry approaches. Chem. Phys. Lett. 2000, 319, 223. [CrossRef]

143. Caballol, R.; Castell, O.; Ilias, F.; Moreira, I.P.; Malrieu, J.P. Remarks on the Proper Use of the Broken Symmetry Approach to Magnetic Coupling. J. Phys. Chem. A 1997, 101, 7860-7866. [CrossRef]

144. Rajaraman, G.; Totti, F.; Bencini, A.; Caneschi, A.; Sessoli, R.; Gatteschi, D. Density functional studies on the exchange interaction of a dinuclear Gd(III)-Cu(II) complex: Method assessment, magnetic coupling mechanism and magneto-structural correlations. Dalton Trans. 2009, 3153-3161. [CrossRef] [PubMed]

145. Zhou, J.; Sonnenberg, J.L.; Schlegel, H.B. Theoretical Studies of $\mathrm{An}_{2}^{\mathrm{II}}{ }_{2}\left(\mathrm{C}_{8} \mathrm{H}_{8}\right)_{2}(\mathrm{An}=\mathrm{Th}, \mathrm{Pa}, \mathrm{U}, \mathrm{and} \mathrm{Np})$ Complexes: The Search for Double-Stuffed Actinide Metallocenes. Inorg. Chem. 2010, 49, 6545-6551. [CrossRef] [PubMed]

146. Meskaldji, S.; Belkhiri, A.; Belkhiri, L.; Boucekkine, A.; Ephritikhine, M. Magnetic exchange coupling in imido bimetallic uranium(V) complexes. A relativistic DFT study. C. R. Chimie 2012, 15, 184-191. [CrossRef]

147. Meskaldji, S.; Zaiter, A.; Belkhiri, L.; Boucekkine, A. A relativistic DFT study of magnetic exchange coupling in ketimide bimetallic uranium(IV) complexes. Theor. Chem. Acc. 2012, 131, 1151. [CrossRef]

148. Perdew, J.P.; Burke, K.; Ernzerhof, M. Generalized Gradient Approximation Made Simple. Phys. Rev. Lett. 1996, 77, 3865. [CrossRef]

149. Perdew, J.P.; Burke, K.; Ernzerhof, M. Rationale for mixing exact exchange with density functional approximations. J. Chem. Phys. 1996, 105, 9982. [CrossRef]

150. Grimme, S. Semiempirical GGA-type density functional constructed with a long-range dispersion correction. J. Comput. Chem. 2006, 27, 1787. [CrossRef]

151. Gagliardi, L.; Roos, B.O. Quantum chemical calculations show that the uranium molecule U2 has a quintuple bond. Nature 2005, 433, 848-851. [CrossRef]

152. Macchia, G.L.; Brynda, M.; Gagliardi, L. Quantum Chemical Calculations Predict the Diphenyl Diuranium Compound [PhUUPh] To Have a Stable 1Ag Ground State. Chem. Int. Ed. 2006, 45, 6210-6213. [CrossRef]

153. Cavigliasso, G.; Kaltsoyannis, N. Metal-metal bonding in molecular actinide compounds: Electronic structure of $\left[\mathrm{M}_{2} \mathrm{X}_{8}\right]^{2-}(\mathrm{M}=\mathrm{U}, \mathrm{Np}, \mathrm{Pu} ; \mathrm{X}=\mathrm{Cl}, \mathrm{Br}, \mathrm{I})$ complexes and comparison with d-block analogues. Dalton Trans. 2006, 5476-5483. [CrossRef] [PubMed]

154. Roos, B.O.; Borin, A.C.; Gagliardi, L. Reaching the Maximum Multiplicity of the Covalent Chemical Bond. Angew. Chem. Int. Ed. 2007, 46, 1469-1472. [CrossRef] [PubMed]

155. Teyar, B.; Belkhiri, L.; Costuas, K.; Boucekkine, A.; Meyer, K. Electronic Structure and Magnetic Properties of Dioxo-Bridged Diuranium Complexes with Diamond-Core Structural Motifs: A Relativistic DFT Study. Inorg. Chem. 2016, 55, 2870-2881. [CrossRef] [PubMed]

156. Hohloch, S.; Pankhurst, J.R.; Jaekel, E.E.; Parker, B.F.; Lussier, D.J.; Garner, M.E.; Booth, C.H.; Love, J.B.; Arnold, J. Benzoquinonoid-bridged dinuclear actinide complexes. Dalton Trans. 2017, 46, 11615-11625. [CrossRef] [PubMed]

157. Grimme, S.; Ehrlich, S.; Goerigk, L. Effect of the damping function in dispersion corrected density functional theory. J. Comp. Chem. 2011, 32, 1456. [CrossRef]

158. Lu, J.; Guo, M.; Tang, J. Chem. Recent Developments in Lanthanide Single-Molecule Magnets. Asian J. 2017, 12, 2772-2779. [CrossRef] [PubMed]

159. Antunes, M.A.; Coutinho, J.T.; Santos, I.C.; Marçalo, J.; Almeida, M.; Baldoví, J.J.; Pereira, L.C.J.; Ariño, A.-G.; Coronado, E. A Mononuclear Uranium(IV) Single-Molecule Magnet with an Azobenzene Radical Ligand. Chem. Eur. J. 2015, 21, 17817-17826. [CrossRef]

160. Solis-Céspedes, E.; Páez-Hernández, D. Modeling the electronic states and magnetic properties derived from the f1 configuration in lanthanocene and actinocene compounds. Dalton Trans. 2017, 46, 4834-4843. [CrossRef]

161. AlDamen, M.A.; Clemente-Juan, J.M.; Coronado, E.; Marti-Gastaldo, C.; Gaita-Arino, A. Mononuclear Lanthanide Single-Molecule Magnets Based on Polyoxometalates. J. Am. Chem. Soc. 2008, 130, 8874-8875. [CrossRef] 
162. AlDamen, M.A.; Cardona-Serra, S.; Clemente-Juan, J.M.; Coronado, E.; Gaita-Arino, A.; Marti-Gastaldo, C.; Luis, F.; Montero, O. Mononuclear Lanthanide Single Molecule Magnets Based on the Polyoxometalates $\left[\mathrm{Ln}\left(\mathrm{W}_{5} \mathrm{O}_{18}\right)_{2}\right]^{9-}$ and $\left[\operatorname{Ln}\left(\beta_{2}-\mathrm{SiW}_{11} \mathrm{O}_{39}\right)_{2}\right]^{13-}\left(\mathrm{Ln}^{\mathrm{III}}=\mathrm{Tb}, \mathrm{Dy}, \mathrm{Ho}, \mathrm{Er}, \mathrm{Tm}\right.$, and $\left.\mathrm{Yb}\right)$. Inorg. Chem. 2009, 48, 3467-3479. [CrossRef]

163. Lukens, W.W.; Speldrich, M.; Yang, P.; Duignan, T.J.; Autschbach, J.; Kögerler, P. The roles of 4f- and 5f-orbitals in bonding: A magnetochemical, crystal field, density functional theory, and multi-reference wavefunction study. Dalton Trans. 2016, 45, 11508-11521. [CrossRef] [PubMed]

164. Lam, O.P.; Anthon, C.; Heinemann, F.W.; O'Connor, J.M.; Meyer, K. Structural and Spectroscopic Characterization of a large-Separated Uranium Benzophenone Ketyl Radical Complex. J. Am. Chem. Soc. 2008, 130, 6567-6576. [CrossRef] [PubMed]

165. Castro-Rodriguez, I.; Nakai, H.; Zakharov, L.N.; Rheingold, A.L.; Meyer, K. A linear, O-coordinated eta ${ }^{1}-\mathrm{CO}_{2}$ bound to uranium. Science 2004, 305, 1757-1759. [CrossRef] [PubMed]

166. Zhang, Y.Q.; Luo, C.L.; Wang, B.W.; Gao, S. Understanding the magnetic anisotropy in a family of N2(3-) radical-bridged lanthanide complexes: Density functional theory and ab initio calculations. J. Phys. Chem. A 2013, 117, 10873-10880. [CrossRef] [PubMed]

167. Demir, S.; Jeon, L.-R.; Long, J.R.; Harris, D. Radical ligand-containing single-molecule magnets. Coord. Chem. Rev. 2015, 289-290. [CrossRef]

168. Sousa, S.F.; Fernandes, P.A.; Ramos, M.J. General Performance of Density Functionals. J. Phys. Chem. A 2007, 111, 10439-10452. [CrossRef] [PubMed]

169. Greif, A.H.; Hrobàrik, P.; Autschbach, J.; Kaupp, M. Giant spin-orbit effects on ${ }^{1} \mathrm{H}$ and ${ }^{13} \mathrm{C}$ NMR shifts for uranium(VI) complexes revisited: Role of the exchange-correlation response kernel, bonding analyses, and new predictions. Phys. Chem. Chem. Phys. 2016, 18, 30462-30474. [CrossRef] [PubMed]

170. Mounce, A.M.; Yasuoka, H.; Koutroulakis, G.; Lee, J.A.; Cho, H.; Gendron, F.; Zurek, E.; Scott, B.L.; Trujillo, J.A.; Slemmons, A.K.; et al. Nuclear Magnetic Resonance Measurements and Electronic Structure of $\mathrm{Pu}(\mathrm{IV})$ in $\left[(\mathrm{Me})_{4} \mathrm{~N}_{2} \mathrm{PuCl}_{6}\right.$. Inorg. Chem. 2016, 55, 8371-8380. [CrossRef]

171. Polinski, M.J.; Garner, E.B.; Maurice, R.; Planas, N.; Stritzinger, J.T.; Parker, T.G.; Cross, J.N.; Green, T.D.; Alekseev, E.V.; Van Cleve, S.M.; et al. Unusual structure, bonding and properties in a californium borate. Nat. Chem. 2014, 6, 387-392. [CrossRef]

172. Cary, S.K.; Vasiliu, M.; Baumbach, R.E.; Stritzinger, J.T.; Green, T.D.; Diefenbach, K.; Cross, J.N.; Knappenberger, K.L.; Liu, G.; Silver, M.A.; et al. Emergence of californium as the second transitional element in the actinide series. Nat. Commun. 2015, 6, 6827. [CrossRef]

173. Adamo, C.; Barone, V. Toward reliable density functional methods without adjustable parameters: The PBE0 model. J. Chem. Phys. 1999, 110, 6158. [CrossRef]

174. Vydrov, O.A.; Scuseria, G.E. Assessment of a long-range corrected hybrid functional. J. Chem. Phys. 2006, 125, 234109. [CrossRef] [PubMed]

175. Vydrov, O.A.; Heyd, J.; Krukau, A.; Scuseria, G.E. Importance of short-range versus long-range Hartree-Fock exchange for the performance of hybrid density functionals. J. Chem. Phys. 2006, 125, 074106. [CrossRef] [PubMed]

176. Tao, J.M.; Perdew, J.P.; Staroverov, V.N.; Scuseria, G.E. Climbing the Density Functional Ladder: Nonempirical Meta-Generalized Gradient Approximation Designed for Molecules and Solids. Phys. Rev. Lett. 2003, 91, 146401. [CrossRef] [PubMed]

177. Autillo, M.; Guerin, L.; Bolvin, H.; Moisya, P.; Berthon, C. Magnetic susceptibility of actinide(III) cations: An experimental and theoretical study. Phys. Chem. Chem. Phys. 2016, 18, 6515-6525. [CrossRef] [PubMed]

178. King, D.M.; Cleaves, P.A.; Wooles, A.J.; Gardner, B.M.; Chilton, N.F.; Tuna, F.; Lewis, W.; McInnes, E.J.L.; Liddle, S.T. Molecular and electronic structure of terminal and alkali metal-capped uranium(V) nitride complexes. Nat. Commun. 2016, 7, 13773. [CrossRef] [PubMed]

179. Myers, A.J.; Rungthanaphatsophon, P.; Behrle, A.C.; Vilanova, S.P.; Kelley, S.P.; Lukens, W.W.; Walensky, J.R. Structure and properties of $\left[\left(4,6-\mathrm{tBu}_{2} \mathrm{C}_{6} \mathrm{H}_{2} \mathrm{O}\right)_{2} \mathrm{Se}\right]_{2} \mathrm{An}(\mathrm{THF})_{2}, \mathrm{An}=\mathrm{U}, \mathrm{Np}$, and their reaction with p-benzoquinone. Chem. Commun. 2018, 54, 10435-10438. [CrossRef]

(C) 2019 by the authors. Licensee MDPI, Basel, Switzerland. This article is an open access article distributed under the terms and conditions of the Creative Commons Attribution (CC BY) license (http://creativecommons.org/licenses/by/4.0/). 